\title{
CIVIC CRAFTING: THE POTENTIAL OF MINECRAFT FOR MUNICIPAL CIVIC ENGAGEMENT
}

\author{
By Lisa Ward Mather \\ BA, The King's College, 1990 \\ MA, University of Alberta, 1996 \\ $\mathrm{PhD}$, University of Alberta, 2002 \\ A Major Research Paper \\ presented to Ryerson University \\ in partial fulfillment of the requirements for the degree of \\ Master of Planning \\ in \\ Urban Development
}

Toronto, Ontario, Canada, 2014

(C) Lisa Ward Mather 2014 


\section{Author's Declaration}

I hereby declare that I am the sole author of this major research paper. This is a true copy of the major research paper, including any required final revisions, as accepted by my examiners.

I authorize Ryerson University to lend this major research paper to other institutions or individuals for the purpose of scholarly research.

I further authorize Ryerson University to reproduce this major research paper by photocopying or by other means, in total or in part, at the request of other institutions or individuals for the purpose of scholarly research.

I understand that my major research paper may be made electronically available to the public. 


\title{
CIVIC CRAFTING: THE POTENTIAL OF MINECRAFT FOR MUNICIPAL CIVIC ENGAGEMENT
}

\author{
(C) Lisa Ward Mather 2014 \\ Master of Planning \\ in \\ Urban Development \\ Ryerson University
}

\begin{abstract}
Minecraft, the popular video game, shows promise as a planning engagement tool: it allows players to experience and manipulate a three-dimensional environment, it is easy to learn and understand, it is engaging and immersive, it is adaptable, and it has already begun to be used for geodesign and planning engagement. However, this game has not yet been studied to determine how it could best be used for this purpose. Using an analysis of key informant interviews, this study seeks to address this deficit and reflect on the ways in which this game could help planners achieve various engagement goals. Key findings in this study address Minecraft's usefulness as a visualization tool, its role in building trust, the place of play in planning, and the challenges associated with conducting an accessible, interactive online engagement using Minecraft.
\end{abstract}

Keywords: Minecraft, civic engagement, serious games, urban planning 


\section{Acknowledgements}

I would like to thank my supervisor, Dr. Pamela Robinson, for her insight, optimism, and good-humoured support throughout the process of writing this research paper. While planning the project with Pamela, I was often struck by, and grateful for, the depth of her practical and academic knowledge. There is no doubt that her critique has had a profoundly positive effect on this research paper.

I also would like to thank my second reader, Dr. Nina-Marie Lister. I appreciate her help in honing this project, particularly because I have met few professors that have such a keen critical eye.

This research paper could not have happened without the generosity of my twelve key informants. I can not name them here, but I am very grateful for their willingness to spend time with me, talking about civic engagement and Minecraft. These interviews provided me not only with data for this research paper, but also many enjoyable hours of conversation with interesting, experienced and intelligent professionals. These interviews were a valuable educational experience and a genuine pleasure to conduct.

I owe much gratitude to my husband, Paul, for sparking my interest in urban planning in the first place, supporting me while in this program, talking with me about my work, and occasionally making dinner. I would also like to thank my children, Katie, Sam, and Jane, for tolerating my absences, preoccupation, and decreased production of baked goods. You can expect some cookies in the near future! 


\section{Table of Contents}

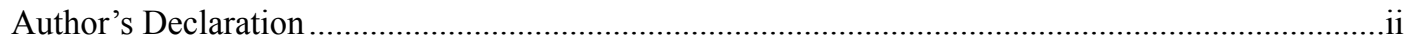

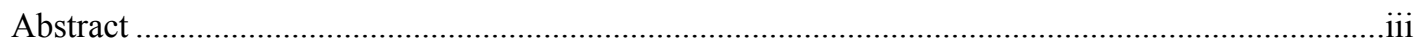

Acknowledgements ............................................................................................................

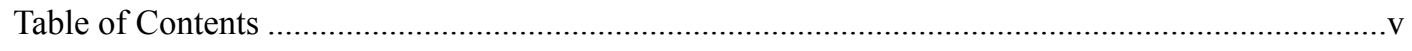

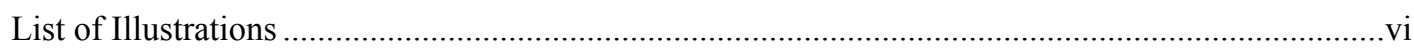

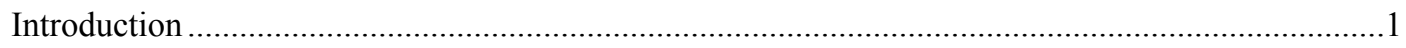

Literature Review: Is there a Case for (Digital) Engagement? .......................................................

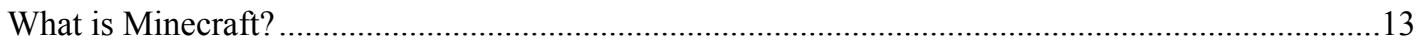

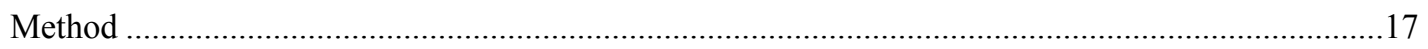

Key Findings ………

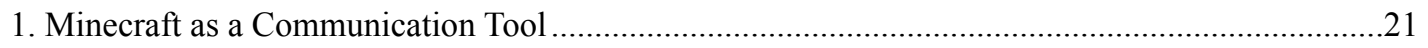

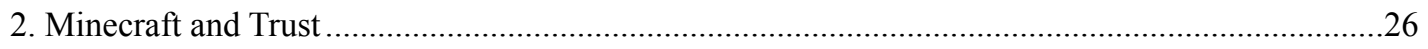

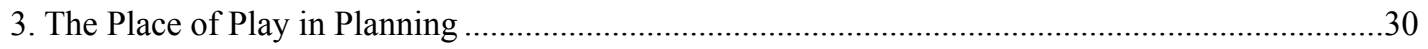

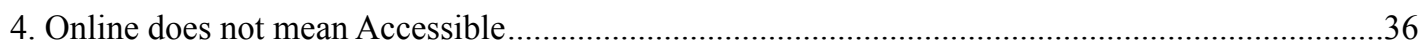

5. The Most Promising Applications of Minecraft for Planning Engagement .......................................38

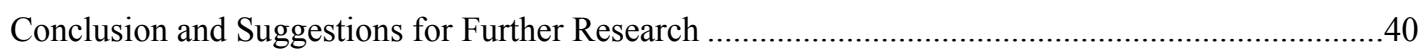

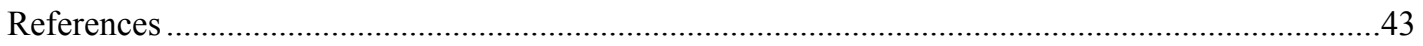




\section{List of Illustrations}

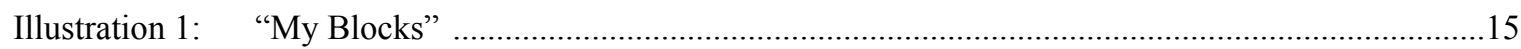

Retrieved from: http://mojang.com/2011/10/minecraft-empowers-people-to-change-their-block/

Illustration 2: Block by Block: a model of a public space in Kiritpur, Nepal. . . .16

Retrieved from: blockbyblock.org 


\section{Introduction}

Since it first appeared in 2009, the video game Minecraft has sold millions of copies and developed an enormous, dedicated fan base. The game, which draws players into the challenges of building and surviving in a distinctive three-dimensional landscape, inspires them to experiment with virtual space. Considering that planners often struggle to motivate people to think about space in the real world, it is worth considering if Minecraft could have a role in planning engagement.

Minecraft could be a powerful addition to planners' suite of civic engagement tools. This game shows promise for several reasons: it allows players to experience and manipulate a three-dimensional environment, it is easy to learn and understand, it is engaging and immersive, it is adaptable, and it has already begun to be used for geodesign and planning engagement (Majury 2013, Ordnance Survey 2013, Manneh 2011 and 2012). It is difficult to know the extent of Minecraft's applicability, or how planners could best use it, because planning scholars and researchers have not yet studied this game ${ }^{1}$. This study will address this deficit by focusing on the following research question:

What potential does Minecraft have for educating the public about land use planning processes and engaging them in those processes?

In recent years, planning researchers and practitioners have increasingly looked to information and communication technologies (ICT), including video games, to improve civic engagement processes. Digital tools could attract more people to these processes, more effectively educate them, or more efficiently collect their thoughts and ideas. Understanding the potential of ICT methods for planning engagement will require ongoing research. Thus far, research into the usefulness of ICT for planning has been encouraging. However, it is clear that when planners incorporate digital tools into municipal planning processes, they need to carefully match these tools to the particular engagement tasks for which they are best suited (Hoene, Kingsley and Leighninger 2013).

Planning engagement initiatives are complex and can have a variety of goals. ICT tools can achieve some engagement goals more readily than others. For instance, some of these tools work well in educating a broad spectrum of citizens about community issues, but do not provide a good forum for conversation around those issues. Others could help people visualize a large scale redevelopment in their city, but do not help neighbours resolve disputes over minor variances.

${ }^{1}$ Of the research that has been done, most of it explores Minecraft's potential pedagogical applications (Hall 2013). 
Many different kinds of ICT tools have been used to involve members of the public in planning their communities. Some planners have used social media platforms, such as Facebook, Twitter and Flickr, to keep people informed about planning issues and initiatives in their neighbourhoods. Web applications, such as i-neighbors, Front Porch Forum, and EveryBlock, have been developed specifically in order to help community members connect with each other and be more aware of what is going on in their neighbourhoods (Apostol et al 2012). Other applications like SeeClickFix and Public Stuff allow citizens to forward concerns to city governments in order to build responsiveness. Planning practitioners and researchers have also begun to investigate how video games from SimCity to Second Life, could change and improve engagement processes (Bers, 2010, Bleumers et al 2012, Blumberg et al 2013, Gordon et al 2012, Jenkins 2006, Kahne et al 2009).

Video games are increasingly being recognized as effective civic engagement tools. They can provide community members with knowledge, skills or experiences that facilitate their involvement in many aspects of civic life, including land use planning. For instance, MMORP (massively multiplayer online role-playing) games such as World of Warcraft and Second Life may, researchers have argued, provide immersive social experiences that prepare participants for real life civic engagement (Blumberg et al 2013). Also, games like those in the Civilization and SimCity series may help users develop skills that make them more thoughtful and capable democratic participants, such as the ability to consider and account for complex social forces (Bers 2010). There are also games that have been designed specifically for communicating planning information and soliciting public input on planning issues. One such "serious game" (Blumberg et al 2013) is Community PlanIt, which was developed by Emerson College's Engagement Game Lab. This platform uses games to interest and involve community members in the planning process (Gordon et al, 2011).

This research study will focus on one game in particular-Minecraft—and will consider its potential for planning engagement. This study will identify Minecraft's strengths and weaknesses as an engagement tool, as well as the engagement situations for which this game is best suited. Minecraft could help planners achieve a wide range of engagement objectives and address several problems related to public engagement. For instance, it may be easier for community members to visualize a change to their urban environment by playing Minecraft than by looking at and responding to a map or drawing. Because Minecraft gameplay is simple and intuitive, and because it is set in an easily-manipulable 3D world, it is "a great way to visualize urban planning ideas without necessarily having architectural training" (Senior 2012). 
As many teachers have already discovered, Minecraft can be an effective educational tool. Planners could use this game to teach the public about planning concepts, or about particular planning situations. In this way it could help the public provide informed feedback and improve planning outcomes.

Also, because Minecraft is customizable, planners could use it to engage people in many different kinds of planning conversations and experiences. Through an avatar, Minecraft players could experience an urban space, or they could build their own space. Also, players could encounter these spaces alone, or as part of a cooperative group. One of the many benefits of cooperative group play is that users who interact in a shared space can experience a "participatory culture" (Jenkins et al, 2006) which offers opportunities for civic debate and a choice of civic roles.

Minecraft could also help attract more people to engagement initiatives. Engaging a broad range of citizens in planning engagement processes is an ongoing problem for planners (Bleumers et al 2012). Because Minecraft provides players with an immersive, fun environment, this game could help motivate people's enthusiastic participation in a conversation about planning ${ }^{2}$. Further, the open-ended nature of the Minecraft environment encourages players' creativity and experimentation, and stimulates their deep engagement with a project (Adams 2012, p. 12).

Considering planners' continuing need for effective engagement strategies, the promise of ICT methods in general, and of Minecraft in particular, this research study is timely and relevant to current debates in planning scholarship. This study not only takes a helpful first step towards understanding Minecraft's potential as a tool for planning engagement, but also adds to discussions about civic engagement through video games, and the challenges that planners face when engaging the public. Ultimately, it seeks to support planners and engagement professionals who are looking for new ways to conduct planning engagement and address long-standing engagement dilemmas.

\footnotetext{
${ }^{2}$ For instance, a Toronto middle-school teacher found that his students were particularly engaged in and thoughtful about their project focusing on environmental resource use because they could experience sustainable planning when they built a sustainable town in Minecraft (Adams 2012).
} 


\section{Literature Review: Is there a Case for (Digital) Engagement?}

The story of how public engagement became central to planning practice in North America is usually told beginning in the 1950s and 60s, with the citizenry — angered by "urban renewal" and freeway construction programs, and empowered by the civil rights movement—demanding a meaningful voice in city planning ${ }^{3}$. The dissatisfied public argued that the planning process was undemocratic and that engagement methods failed to direct urban planning in a way that would serve their needs. Many planning scholars agreed. Particularly influential was Sherry Arnstein's 1969 critique, in which she introduced the "ladder of participation." Arnstein's distinction between differing degrees of public empowerment drew attention to the routine disconnection between public engagement and decision-making processes, and went on to inform countless discussions about planning engagement (Lane 2005).

In the decades that followed, planning processes were ultimately transformed. Whereas public involvement in land use planning was previously limited to the public's receipt of information about city plans, it began to involve a spectrum of activities. The term "engagement" ${ }^{4}$ now has a wide range of meanings. In this study, the term "engagement" will be used as an umbrella term, and more precise language will be used to distinguish between the various types of engagement activities that involve differing degrees of public involvement and empowerment. These include: outreach, or the process of attracting the public to a conversation about planning, communication of information (or the explanation of a thought process), the collection of feedback on a planning issue, education about planning principles or about a specific planning project, and dialogue for the purpose of generating new ideas or achieving broader understanding.

Planning departments are now required and expected to be proactive in their involvement of a wide range of citizens, and planners have come under increasing pressure "to create opportunities for broader participation" (Sandercock 2005, p. 438). Not only is public engagement a legal requirement of many municipal planning departments, but scholars have established the benefits of engagement (Creighton 2005, Yang and Pandey 2011), and, importantly, many planners share a faith in those benefits (Brabham 2009, Creighton 2005, Innes and Booher 2000). Public engagement can help a plan obtain public support (Burby, 2003, Brody et al., 2003), and can help planners craft plans that better serve the needs of the public (Van Herzele 2004).

${ }^{3}$ Cullingworth (1984) points out that the "situation in Canada was not as dramatic as in the U.S.A.: there was no federal highway program (apart from the Trans-Canada Highway); but the issue was in essence the same" (4).

${ }^{4}$ In this study, the term "engagement" will be used, although the researcher acknowledges that many planners and planning researchers use the term "participation" to speak about the same range of activities through which the public can learn about or respond to land-use planning decisions. 
The public is provided with opportunities to participate in land use planning in Ontario through the Planning Act. The Act requires that the public be granted access to information (1.0.1), that they receive notice about public meetings and open houses, and it gives them the right to appeal land use decisions. Municipalities hold Public Meetings when considering applications for changes to zoning bylaws, plans of subdivision, and amendments to the Official Plan ${ }^{5}$. Public Meetings are held, in part, to provide a public forum in which citizens can consider and debate the application. The Act stipulates that every person who attends a public meeting is allowed to participate by speaking at the meeting (19.2). It also allows that anyone may provide written statements to City Council before a plan is adopted. The Provincial Policy Statement, 2014 is issued under the authority of section 3 of the Planning Act. Although it recognizes that "the diversity of Ontario and that local context is important," (Ontario Ministry of Municipal Affairs and Housing 2014, p. 2), the Statement does not speak of engagement, other than the need to consult with Aboriginal communities "on planning matters that may affect their rights and interests" (p. 4).

Considering legislative requirements, like those in Ontario's Planning Act, that the public be informed and consulted about land use planning, the planning profession has become increasingly involved with the problem of how to meaningfully involve the public (Bryson et al 2013). Klosterman (2001) argues that, because planning is an "inherently political and social process of interaction, communication, and social design," the methods of planning engagement are crucial (p. 11). "[T]he way in which planners transmit information may be more important than what they say" because poorly chosen engagement methods can undermine the planner's relationship with the public and impede their communication (Klosterman 2001, p. 10).

Further, the problem of how to engage the public has continuing relevance because there is a lingering sense, despite the agreement that planning can be improved by public input, that the outcomes of engagement initiatives are often not substantive or meaningful, and they often do not facilitate effective communication (Mees and Dodson, 2007). For instance, traditional consultation processes, such as public hearings, continue to be condemned by planning theorists and practitioners. These processes have been most commonly critiqued for allowing the disproportionate influence of a limited group (Flyvbjerg 1998, Hibbard and Lurie, 2000), failing to interest or productively engage a wide range of people (Gordon et al 2011), and failing to improve planning decisions (Innes and Booher 2004). A particularly powerful critical articulation of the failings of traditional engagement processes has been offered by the "communicative" theorists including Judith Innes and David Booher (2000), Patsy Healey (1997), and John Forester (1989). These theorists argue that a diverse group of stakeholders

\footnotetext{
${ }^{5}$ In Toronto, the City's four Community Councils are responsible for Public Meetings. When the application's significance is city-wide, this responsibility falls to the Planning and Growth Management Committee.
} 
should have a substantive role in making land-use planning decisions and they advocate for a planning process that is more interactive and collaborative.

Many planners have responded to this critique by developing new engagement processes and tools that aim to "enlarge the participation process, [and] maximize and diversify stakeholder input in the designing of solutions for urban problems" (Brabham 2009, p. 243). Starting in the 1980s, planners began to experiment with "more grouporiented and deliberative forms... [A]t the local level in particular, in order to involve more people, a variety of new forms of participation" were introduced (Kubicek 2010, p. 174) ${ }^{6}$, and new ways to meaningfully engage the public were investigated (Gordon et al 2011, Innes and Booher 2000, Kubicek 2010, p 174). Some of these new, more interactive, strategies include focus groups, citizen panels, public surveys, design charrettes, participatory budgeting processes, workshops, roundtable discussions, meetings-in-a-box ${ }^{7}$, and public education initiatives ${ }^{8}$.

In recent years, planning researchers and practitioners have increasingly looked to information and communication technologies (ICT) to improve civic engagement processes. Starting around the beginning of the millennium, there was a sense that these technologies held great promise for public engagement and that "an acceleration of technologically enhanced participatory planning tools would occur” (Brail and Klosterman 2001). Daren Brabham (2009), for instance, although unwilling to dismiss traditional participation methods, suggests that online participation is a logical next step considering the difficulties planners currently face around engaging the public: "Simply put, with so much difficulty in executing the face-to-face public participation component of a planning project, we should begin to think beyond the bounds of what might constitute public involvement in the first place" (p. 246). Some of the tools that have emerged in recent years include web pages, social media (such as Facebook and Twitter), crowdsourced information collection, wikis, blogs, online chats, electronic voting, open data platforms, online mapping tools, online surveys, as well as video games. These tools can facilitate a variety of

\footnotetext{
${ }^{6}$ By the end of that decade, there was widespread agreement that public participation in planning was necessary for ethical reasons, to improve plan quality, and in order to increase the chance that they will be implemented (Goodspeed 2008).

${ }^{7}$ For example, Metrolinx produced a Conversation Kit in order to facilitate public discussion around how to fund transit. Similar tools have been developed by other planning organizations, including planET, Hillsborough Planning Commission, and Oregon's Washington County.

8 Examples of educational programs include those offered by the Citizens Planning Institute, the Centre for City Ecology, the Box Cities program, and the various initiatives offered by municipalities for World Town Planning Day.
} 
engagement goals, such as outreach (raising awareness), information sharing, collecting public feedback, education, dialogue, and conflict resolution ${ }^{9}$.

Research into the usefulness and efficiency of digital tools in comparison with traditional methods is ongoing, as is analysis of the barriers to their effective use. This research has, thus far, been encouraging, showing that digital engagement methods can have a variety of benefits (Twitchen and Adams 2011). One of the benefits of ICT technologies, scholars suggest, is that they can more easily involve greater numbers of people, and more diverse groups of people, into engagement processes (Brabham 2009). It can be difficult to gather a wide range of community representatives together for a face-to-face meeting, if not "impossible only on the basis of logistics of meeting times and travel schedules. For projects that cover broad geographical areas, bringing everyone together in one space can be prohibitively expensive" (Hollander 2011, p. 589). Digital methods could help solve problems like this one, because they are easy and convenient to access (Zhong 2011, Mandarano et al 2010, Hoene, Kingsley and Leighninger 2013). Online participation can also be less time-consuming for participants than traditional methods, and, in some cases, can be less expensive for governments to implement (Twitchen and Adams 2011). Importantly, many citizens have begun to expect that they should be able to participate using digital tools, including web pages, social media, and mobile applications (Fredericks and Foth 2013).

Digital tools may also allow members of the public to take a more active role in planning their communities (Apostol et al 2012, Batty et al 2010). For instance, because these methods can provide sophisticated and accessible visual information, they can communicate planning ideas more effectively to the public (Bamberg 2013). Having access to digital information and tools may empower community members to address problems in their communities. In this way, ICT tools can not only reach, but also possibly empower, a larger, more diverse group than do traditional methods (Horelli and Kaaja 2002, Kubicek 2010). Evangelia Berdou (2011), for instance, suggests that new digital mapping technologies can empower communities and vulnerable groups. The asynchronous nature of digital engagement processes may also allow some participants a freer expression of ideas (Gordon 2012, Evans-Cowley and Hollander 2010). Kevin C. Desouza and Akshay Bhagwatwar (2012) describe how open data applications can allow citizens to leverage data and develop solutions to local problems. Digital applications can also connect citizens to each other in order to set local priorities, support community activism,

\footnotetext{
${ }^{9}$ This research study will focus on certain of these engagement goals, because of the ways in which Minecraft is most likely to be used for planning engagement. These goals include: attracting a diverse public to planning engagement initiatives, communicating information to the public in order to inform their feedback, education, and collaborating in order to exchange ideas with the public.
} 
facilitate collaboration, and help foster knowledge and local problem-solving (Kolbitsch \& Maurer 2006, Foth et al. 2011, Fredericks and Marcus 2013, Hoene, Kingsley and Leighninger 2013).

Researchers have also associated the use of digital tools with broader social benefits. Some critics are optimistic that digital tools can help improve transparency (Gibson 2006) ${ }^{10}$ and may help "restore faith in planning processes" (Twitchen and Adams 2011). According to Conroy and Gordon (2004), public meetings conducted with digital tools can improve public knowledge, satisfaction and commitment levels in comparison with traditional public meetings (see also Evans-Cowley and Hollander 2010) ${ }^{11}$. Couldry, Livingston, \& Markham (2007) argue that access to digital media can orient people to their larger context, while Bakker and deVreese (2011) find that "interactive online communication" and online news use are "positively related to [political] participation," (also see Weber et al 2003) ${ }^{12}$. Digital tools may also have the potential to build social capital (Mandarano et al 2010, Brody et al 2003, Burby 2003, Bakker and de Vreese 2011).

Video games are increasingly being studied for their ability to improve civic engagement processes. These games may provide community members with knowledge, skills or experiences that facilitate their involvement in many aspects of civic life, including land use planning. Some scholars have studied the lessons that video games have for learning (Gee 2007a and 2007b, Ito and Bittanti 2010, Squire and Barab 2004, Bleumers et al 2012), while others have argued that video games are useful for civic education in particular (Bleumers et al 2012, Raphael 2010, Kahne 2009). Some games may provide players with opportunities to experience the complexity of an urban environment and practice civic skills (Bers 2010). Some scholars have argued that games can also provide immersive social experiences that prepare participants for real life civic engagement (Blumberg et al 2013, Gordon, Schirra and Hollander 2011). Bleumers et al (2012) argue that there is a positive correlation between civic digital game play and civic engagement and suggests that games can empower their players by motivating learning, providing an opportunity for trial and error testing, and facilitating social interaction (see also Kahne et al 2008). Games may help solve some civic engagement problems, such as the difficulty of attracting public participation (Gordon and Baldwin-Philippi 2014, Poplin 2011). Game designer Nicole Lazzaro, for example, has argued that games "are self-motivating systems" that can "tap into human emotions" and increase engagement (Kamensky 2013).

\footnotetext{
${ }^{10}$ Although, Jenkins et al (2006) argue that there can be a lack of transparency for digital tools.

${ }^{11}$ However, the process of adapting formal civic education programs to new technology has not been thoroughly researched (Haste 2009).

${ }^{12}$ Survey findings from Shah, Kwak, and Holdert (2001) indicate that, when used for information exchange, Internet use was positively correlated with civic life and social trust.
} 
One explanation for how game play can have broader social effects, is offered by Jenkins et al (2006). They argue that games are part of a "participatory culture" that offers opportunities for civic debate and shifts the players' attention from individual self-expression to community involvement (Jenkins et al 2006, also see Bleumers et al 2012). Jenkins et al (2006) describes how digital game play can facilitate empowerment:

Empowerment comes from making meaningful decisions within a real civic context: we learn the skills of citizenship by becoming political actors and gradually coming to understand the choices we make in political terms. Today's children learn through play the skills they will apply to more serious tasks later. The challenge is how to connect decisions in the context of our everyday lives with the decisions made at local, state, or national levels. The step from watching television news and acting politically seems greater than the transition from being a political actor in a game world to acting politically in the "real world." (p. 10)

Current research, according to a report by the European Commission, "hints towards the potential of games as empowerment tools" (Bleumers et al 2012, p. 7). This report seeks to provide "coherent and substantial information on this topic" (p. 7). It concludes that "use of digital games for empowerment and social inclusion carries significant potential" and that further research is warranted (p. 157).

Some scholars, non-profit organization and planning firms have taken note of the potential of video games for civic learning and engagement, and have designed games specifically for communicating planning information and soliciting public input on planning issues. One such "serious game" (Blumberg et al 2013) is Community PlanIt, which was developed by Emerson College's Engagement Game Lab. This platform uses games to interest and involve community members in the planning process and "transform acts of participation into civic learning” (Gordon et al, 2011, Gordon and Baldwin-Philippi 2014). Another online engagement tool, MetroQuest, uses some game-like features to motivate public engagement (MetroQuest, n.d.). Planning and design firm, Sasaki, has also developed a planning game called "Design Your DSM" which was used for "The Tomorrow Plan," a regional planning process in Greater DesMoines, Iowa (Sasaki 2012). An American non-profit organization, Kaboom, also designed a game called "Our Dream Playground," to help communities plan playground projects and raise funds for construction (Kaboom, n.d.).

Although digital tools, including video games, have many possible benefits, and despite the fact that they seem capable of transforming participatory planning practices, the integration of these tools into planning engagement processes has "not occurred at the scale or speed anticipated" (Lee and Theodoropoulos 2012, p. 1222). One explanation for the slow rate at which digital tools have been integrated into planning engagement practices is 
that there are logistical difficulties that accompany the use of any new technique. There are also, however, other reasons that are specific to digital technologies. One such reason is that access to these technologies is not equally distributed, nor are the skills necessary to use and understand them (Stern et al 2009, Twitchen and Adams 2011, Berdou 2011, Gurstein 2011, Mallan et al 2010, Mandarano et al 2010, Evans-Cowley and Conroy 2006). This “digital divide" may affect members of some disadvantaged communities more than others ${ }^{13}$. For example, rural communities that lack broadband internet access cannot use certain online services (Townsend et al 2013).

Digital engagement tools have also been integrated slowly because of concerns around data ownership, data quality, reliability, privacy and confidentiality, and other legal and ethical issues (Twitchen and Adams 2011, Batty et al 2010, Hunter et al 2012). Elwood and Leszczynski (2010) argue that privacy needs to be reconceptualized because of the growing use of new locational technologies. They suggest that "visual forms of information" raise privacy concerns partly because they have different "discursive authority" and are more likely to be "accepted as 'true' or 'accurate"' (p. 11). However, other researchers have found that not all members of the public accept these technologies as useful and legitimate ways through which to learn about and provide feedback regarding changes to their urban environments (Twitchen and Adams 2011, Evans-Cowley and Hollander 2010, Gordon 2012). Some citizens are suspicious of new technologies and can conclude that planners are trying to manipulate them (Innes and Booher 2005, cited by Evans-Cowley and Hollander 2010). In fact, online tools may have less potential to increase participation in public engagement than was previously assumed; some scholars have concluded that online tools do not increase overall engagement, but merely encourage more engagement from those community members who

\footnotetext{
${ }^{13}$ Some researchers have argued that digital tools can actually serve to empower disadvantaged groups: because "ICT allows multi-modal, synchronous or selective representation," some disadvantaged groups could be empowered to provide "criticism, comments, suggestions and impressions" (De Filippi 2011, p. 69, 70). De Filippi (2011) continues to argue that digital tools are more empowering than they are exclusionary: "In order to increase the awareness of citizenship, ICT can be considered as a revolutionary support .... Low cost and friendly tools could help to upgrade the educational level of low incoming people, opening the communities and increasing the sense of belonging to a urban context as well as a neighbourhood. Digital democracy through digital inclusion and e-learning can be aimed in order to let citizen know, participate, share, improve or criticise projects and actions" (p. 67). Another counter to the "digital divide" debate is that access to traditional methods is also not equally distributed (and also may not provide access to members of disadvantaged communities) (Evans-Cowley and Hollander 2010).
} 
already know about and are interested in the subject of an engagement initiative (Fredericks and Foth 2012). In some situations, members of the public prefer face-to-face engagement over online participatory processes $(\text { Garau } 2012)^{14}$.

Despite the fact that the integration of digital tools into the planning process has been slower than expected, the public increasingly expects to be able to participate in planning processes using these tools (Fredericks and Foth 2013, Williamson and Parolin 2013). Information and communication technologies have transformed the way we exchange ideas. Even in 2006, Evans-Cowley and Conroy's research indicated that

citizens have increasing expectations of their planning departments' web sites. Many departments reported that they were being pressured by citizens to provide more interaction.

Fifty-four percent of planning directors reported that they were receiving pressure from citizens to provide more e-government, while 29 percent reported receiving pressure from local officials. (p. 97)

Since that time, the public's expectation has continued to increase (Mandarano et al 2010).

To respond to this public demand, planning departments need to know how and when to use different digital tools. It is clear that when planners incorporate ICT tools into municipal planning processes, they need to carefully match these tools to the particular engagement tasks for which they are best suited (Hoene, Kingsley and Leighninger 2013, Bamberg 2013) ${ }^{15}$. Planners also need to understand how ICT tools fit into traditional engagement and decision-making processes (Horelli and Kaaja 2002, Ask and Grönlund 2008, Berglund 2008, Evans-Cowley and Conroy 2006, Bamberg 2013, Berdou 2011). Understanding the particular strengths and weaknesses of digital engagement tools will require continued research, such as that conducted for this study.

This study offers an analysis of Minecraft's promise as a planning engagement tool. This discussion is informed not only by interviews with key informants, but also by the history of the game, its distinguishing characteristics, and some recent projects that have used Minecraft as a tool for education and engagement. While not

${ }^{14}$ Other challenges around the use of ICT tools include the unsuitability of some tools for certain engagement goals (Bamberg 2013), the lack of information about how technology affects behaviour (Antoniadis and Apostol 2013), the difficulty of setting the conditions for public engagement (Fennell 2013) or interpreting the results of that engagement (Evans-Cowley and Conroy 2006, and lack of staff expertise (Williamson and Parolin 2013, EvansCowley and Conroy 2006). Incorporation can be difficult, in part, because it is challenging for planning departments to be open to, and adapt to this new technology (Berglund 2008, Chadwick 2011, Gordon 2012, Horelli 2002). It can also be hard to identify and measure success (Zhong 2011, Ask and Grönlund 2008, Kubicek 2010). Despite this difficulty, Chiara Garau recognizes the importance of monitoring and measuring results for retaining participants' belief in the relevance and impact of their online engagement.

${ }^{15}$ It is particularly important to understand the appropriate use of digital tools because procuring them can be costly and implementing them may require specialized staff training. 
all of these real-world applications are related to land use planning, they all demonstrate the adaptability of the game and suggest its potential for planning engagement. 


\section{What is Minecraft?}

Minecraft is a video game that can be played on computers, Xbox and Playstation consoles, and Raspberry Pi devices. A simpler, mobile version of the game has also been developed, which allows Minecraft to be played on iPods and smartphones.

Minecraft was developed by an Swedish programmer, Markus Persson (known as Notch), starting in 2009. Between that time and and the game's official release date, November 18, 2011, players could purchase and play the game, although it changed occasionally when updates were released. These updates would alter the game's functionality and improve it, in part, in response to players' requests and comments. Persson and Jakob Porsér formed the independent company, Mojang, in September of 2010. The "pocket edition" was released in 2011, the console versions began to appear in 2012, and the Raspberry Pi version was released in 2013.

The game has had marked commercial success, having sold more than 30 million copies to date. This success is particularly striking considering that Minecraft was developed by an independent company, without the help of outside investors. Minecraft's success is not just apparent in its game sales: it has also become a recognizable part of pop culture. Merchandising based on characters and objects from the game - which all share the game's distinctive low-resolution pixellated, cube aesthetic — is now readily available. Players can buy plushes, clothing, action figures, lamps, imaginative toys, and even a line of Minecraft-themed Lego sets.

Minecraft gameplay has evolved in recent years, although it remains simple to learn. Initially allowing the player to do little more than mine for resources, craft objects and build structures, the game now allows players to do any number of activities, including farming, breeding animals, fighting monsters (called mobs), devising electrical circuits, and constructing machines. Most players do some building, using various block-shaped materials. Depending on the mode that they choose, players will have instant access to resources (creative mode), or they will have to locate the resources they need in the game world (survival and hardcore modes). Players use these resources to craft objects that they need, such as beds, pick axes, swords, bows, buckets, and so on. Players can include hostile creatures or exclude them from the game, depending on the "difficulty" setting they choose. Minecraft players are largely free to choose how their world works and what they do while playing the game.

Playing Minecraft does not tend to be a linear experience. Minecraft is a true "sandbox" game: it provides players with an open world and allows them to move freely through it, choosing their own goals. Players can play the game like a traditional adventure game, by following a series of steps to find and kill a dragon, called the Enderdragon. Most players, however, choose their own objectives. 
Minecraft can be played alone, in single-player mode, or with other players in multi-player mode. Players often play independently on multi-player servers in the company of other players. Some multi-player Minecraft worlds have been set up with specific, collective goals. Westeroscraft, for example, is a Minecraft world in which players are working together to build a Minecraft version of Westeros, the world described in George R. R. Martin's Game of Thrones fantasy novels. Some Minecraft servers do not attempt to proscribe player activity, but change the conditions within which that activity occurs. For instance, "Hello Miners" is a huge modern city role-playing world. This world has an economy and players must earn money to buy land before they are able to build.

Minecraft has a vibrant, active online community. Thousands of people regularly connect online to collaborate on Minecraft projects. This vibrancy can be attributed to the game's adaptability and openness. Minecraft has a history and a culture of openness - starting from its first days in which it was developed in consultation with players. The lack of restrictions in the Minecraft world encourages players' ingenuity and creativity. This creativity has even extended to modifying the game's code. Many players have developed Minecraft "mods" which change the game's content. Other players have developed "texture packs" which change the appearance of the game. While Mojang does not provide technical support for these altered versions of the game, it does not try to stop players from developing and releasing them. In fact, Mojang has responded to the modding community's sophisticated, but inconsistent, contributions to the game by beginning work on "an official mod API, [which will enable] Mojang to endorse well-tested mods and offer them through a central repository ingame" (Davies 2012).

Minecraft's adaptability has inspired many people to use this game as a tool to address real-life problems and projects. A group of teachers and programmers has developed MinecraftEdu, a version of the game designed to be affordable and accessible for schools. It is currently being used in approximately 2500 schools worldwide (Bristow 2013). Teachers have used Minecraft to teach biology, ecology, physics, geography, chemistry, history, math, engineering, foreign languages, architecture, digital citizenship, and city planning, among other subjects. For example, one teacher gave his students a sustainability challenge in Minecraft, asking them to construct a town with a limited number of building materials. The students' choices in the game began conversations about building materials, economies, industrialization, and renewable energy (Brown 2013).

Minecraft was also used by a Hamilton teacher as an extended project with a Grade 6/7 gifted class. This teacher, Zoe Branigan-Pipe, identified a vacant site in the city and asked the class to plan a development that they thought would benefit the neighbourhood. The project allowed the teacher to address subjects including neighbourhood planning, local history, geography, law, and social studies (Branigan-Pipe 2013). This project 
provides an interesting case study for planners. It demonstrates how planners could use Minecraft to initiate a public discussion about urban change.

Terrain modelling is another recent application of the game. Recently, the Technology Coordinator at the Norwegian Mapping Authority's Hydrographic Service, Boele Kuipers, imported LiDAR-derived data detailing onshore land, and sonar-based underwater data to generate the "first Norwegian combined land and sea terrain model" (Majury 2013). Minecraft is a useful tool for this purpose because its underwater terrain is as complex as its aboveground terrain. Also, Great Britain's national mapping agency, Ordnance Survey, used two digital map products to create a Minecraft world representing 224,000 $\mathrm{km}^{2}$ of Great Britain. They have made the world free for players to download and play in. They describe the world, saying that it "consists of over 22 billion blocks — we think this may be the largest Minecraft world ever built based on real-world data" (Ordnance Survey 2013).

As these projects make clear, Minecraft is being used in ever more interesting and innovative ways to explore real world space in a virtual setting. These projects are also interesting because they demonstrate the improvements that have been made to the technologies that could support the use of Minecraft for planning engagement. Although it is already possible to import GIS city data into Minecraft, this process will become easier as more supporting technologies and processes are developed. As the process of importing city data becomes easier, there will be fewer barriers to using Minecraft for planning engagement in the ways this study is beginning to imagine.

A Swedish museum is also using Minecraft as a geodesign tool. The Swedish Centre for Architecture and Design has brought Stockholm's geographical and infrastructure data into a Minecraft world called "Blockholm." The museum is inviting the public into this world to build a new version of the city. The ultimate goal is to engage citizens in a conversation about what they want Stockholm to be (Swedish Centre for Architecture and Design 2013). The museum's decision to use Minecraft for this project indicates that it recognizes the game's suitability for visioning, which is an application that is also explored in this study.

Minecraft has also been used for urban planning engagement projects. In 2011, an engagement project was initiated in advance of a plan to restore a suburban Swedish housing project. This project, called "Mina Kvarter" or "My Blocks," offered community members the opportunity, through workshops, a Facebook page, and

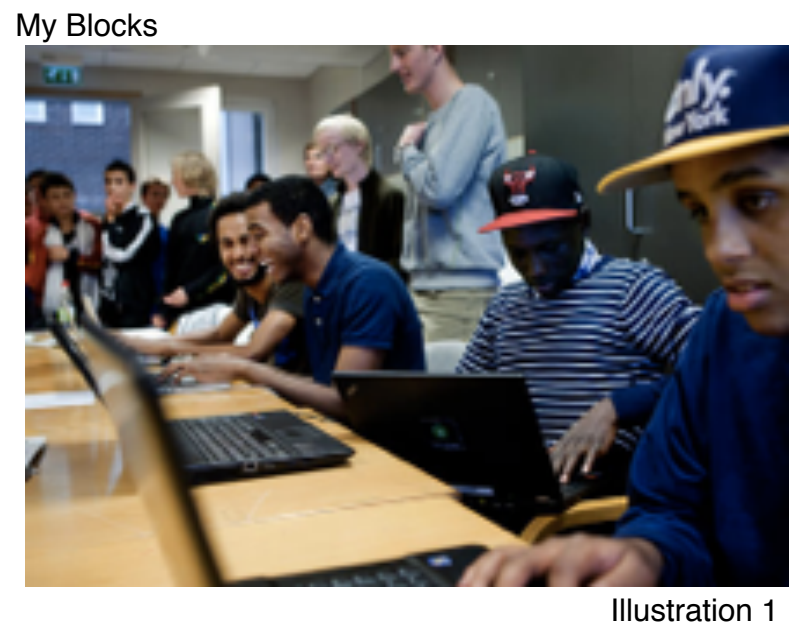


Minecraft, to offer their opinions about what they want their neighbourhoods to look like in the future. The housing project was built on Minecraft servers and citizens were invited to change the buildings, roads, and parks.

Importantly, "[s]everal property owners and construction companies ... committed to use these ideas as [a] basis for the decision making around the reshaping of these projects" (Manneh 2011).

Another planning engagement project has been initiated jointly by the UN and Mojang. "Block by Block" invites young people in third world countries to help plan their communities. A Minecraft building community, Fyre UK, renders the communities in Minecraft, and then the "young people who live in those environments step in and show designers what they'd like to see changed" (Senior 2012). Currently, the project is focusing on communities in various locations around the world, including Les Cayes, Haiti, Jeevanjee Gardens in central Nairobi, and Kiritpur, Nepal.

These real world applications demonstrate Minecraft's potential for planning engagement and confirm the relevance of this study's research question. Through key informant interviews, this study further explores the game's potential and suggests the game's most promising applications.

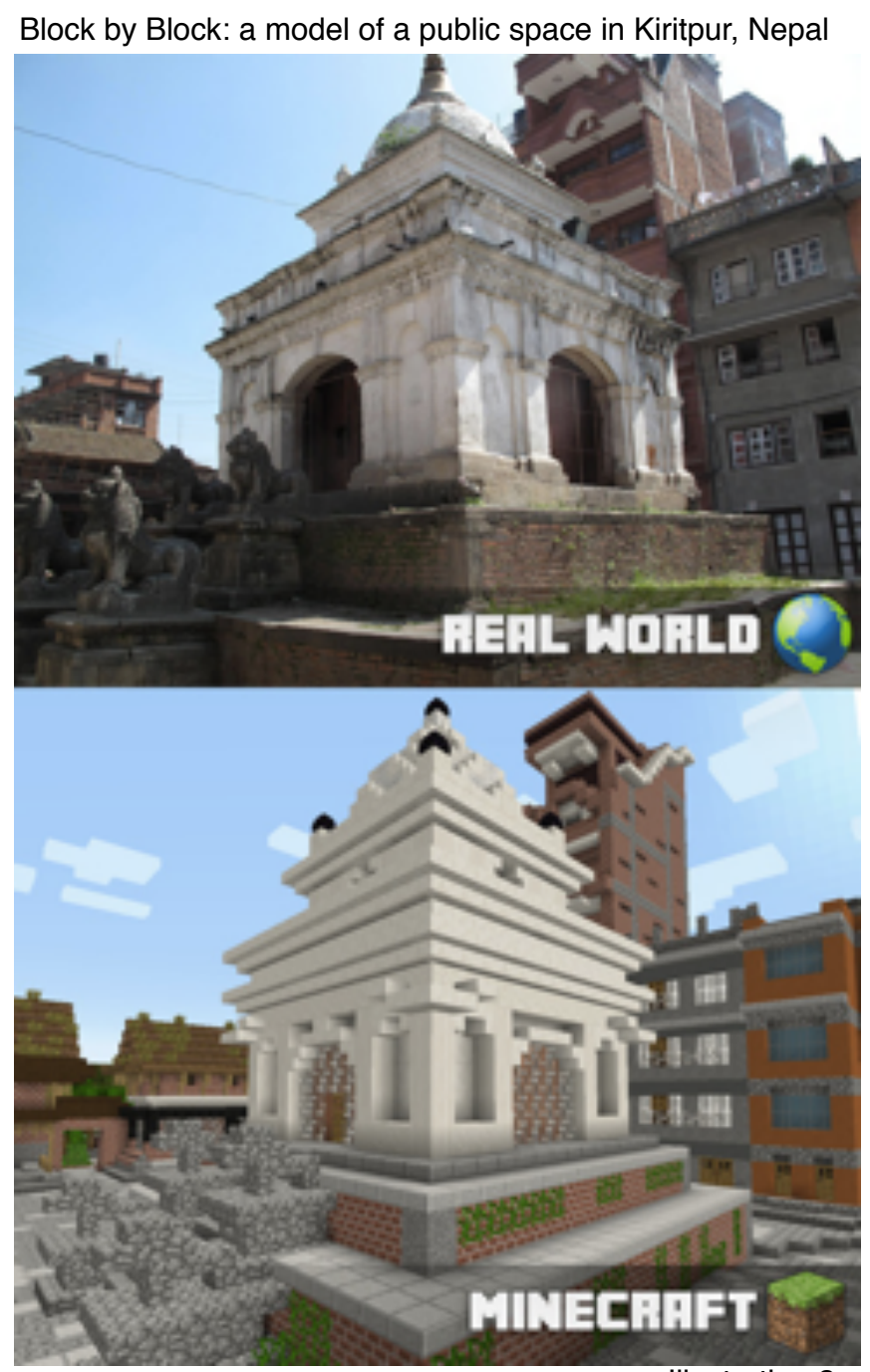

Illustration 2 


\section{Method}

The analysis contained in this research study is contextualized by the preceding literature review of scholarship on planning engagement and the use of ICT tools (including video games) for engagement. It is further informed by the discussion of Minecraft's history, its distinguishing characteristics, and its real-world applications. This information comes from diverse sources, including journals, blogs, web sites, newspapers, and magazines.

The method employed in this study is largely determined by its exploratory nature, and by the fact that there is currently no research on the uses of Minecraft for planning engagement. Considering the lack of previous research, planners and engagement professionals are the best source of information about how and in what context Minecraft could be used to involve the public in land use planning. Because these professionals have a deep understanding of planning engagement's goals, methods, and challenges, they can provide insight into Minecraft's suitability for this purpose.

This research study is based on semi-structured interviews with twelve key informants. In preparation for the key informant interviews, this study was granted approval by the Ryerson University Research Ethics Board. Key informant interviews are used to produce qualitative data for analysis in this study because such interviews are “especially beneficial as part of an initial assessment" of an issue (Parsons 2008). The key informants were chosen for their expertise in, and different perspectives on, the goals and challenges of planning engagement. These interviews were open-ended in nature to allow the interviewer to explore ideas introduced by the interviewees through follow-up questions. As Wilson and Sapsford (2006) explain, "Less-structured methods ... allow the freer exploration of respondents' meanings and beliefs" (p. 5).

The twelve key informants selected for this study include municipal or regional planners and civic engagement professionals with experience in engagement for land use planning. These interviews focused on the engagement strategies previously used by the respondents, including the use of visualization tools, digital tools, interactive tools, and game-like tools. Because the informants were not expected to have in-depth knowledge of Minecraft, the researcher prepared a short (4.3 minute) video about the game and showed it to the informants during the interview. This video describes Minecraft's basic gameplay, its built-in (but optional) objectives, the openness of the Minecraft world, and the ability to play alone or with others. The video also introduces the kinds of projects developed by the Minecraft community, such as massive builds and the construction of mechanical devices. The video mentions the increasingly common use of Minecraft by teachers, and gives examples of several other projects that have employed Minecraft, including the Norwegian terrain modelling project, the Swedish Centre for Architecture and Design's Blockholm project, and the UN's Block by Block project. 
The interviewees were asked to consider if and how Minecraft could be useful to planners in their efforts to educate, exchange information with, or solicit feedback from members of the public. The interviews concluded with questions about how, and to what advantage, Minecraft could be used in specific planning contexts, including Committee of Adjustment hearings, rezonings and redevelopments, and Official Plan reviews. 


\section{Key Findings}

For this research study, twelve interviews were conducted in February and March of 2014. Although a few of the informants in this study had seen a young relative play Minecraft, most of them had little knowledge of the game. The informants' comments about Minecraft were, thus, largely informed by a short video presentation which was made by the researcher for the purposes of this study. Notes were taken during each interviews and, afterwards, the interviews were transcribed. The researcher performed a manual content analysis on the notes and the transcriptions. This analysis involved the identification of key issues and themes in each interview. These themes were identified as significant based partly on the degree to which they addressed the study's research question, and partly on the apparent significance of the theme in the context of the entire body of interviews. This significance was indicated by the frequency with which issues were discussed by the interviewees: interviewees often mentioned issues that were also mentioned by other interviewees. This significance was also indicated by the presence of widespread agreement, or of notable dissension. Respondents' comments on key issues were noted, and thematically correlated with the themes in other interviews. These correlated comments were then compiled to suggest key findings related to the usefulness of Minecraft for planning engagement. These findings also reflect on the kinds of initiatives the game would best serve. This study concludes by suggesting directions for future research.

The researcher has decided to not to provide a coded identification of respondents in this study. This decision has been made because there is no clear pattern in the respondents' answers: they did not fall into discernible "camps" in the interviews. If the respondents had been more obviously positioned on different issues, the usefulness of identifying respondents would have been apparent.

Almost all respondents acknowledged that Minecraft could be useful in some engagement situations. They were also, however, very conscious of how difficult it could be to incorporate this game into existing engagement practices, and they mentioned numerous logistical obstacles. One of the most skeptical respondents explained that attitudes toward digital engagement tools were often over-enthusiastic. This respondent felt it was important to not rely too heavily on such tools because achieving understanding between people - the most important kind of engagement work, according to this respondent — can only happen when you bring people in face-to-face contact with each other. In fact, many of the interviewees were certain of the value of face-to-face engagement methods, particularly for the purpose of dialogue and conflict resolution.

The interviews were rich, with respondents reflecting not only on Minecraft, but also on the challenges of engagement and the difficulty of shaping a meaningful, productive interaction with the public. When reflecting on the influence of specific tools like Minecraft on the success of an engagement initiative, respondents typically took 
one of two positions. Three of twelve respondents deemphasized the role of individual tools in determining the outcome of an engagement initiative. These people felt that helping the public understand the purpose of engagement, and fostering their trust in the process, were goals that could not be solved by using one tool over another. These respondents were more focused on ensuring clarity of purpose in their engagement initiatives rather than looking for new ways to carry those engagements out. Other respondents, however, emphasized the power of particular tools to facilitate the public's understanding and build their trust in the process. These respondents felt that choosing a particular engagement method could help ensure an engagement's success.

Ultimately, all respondents could imagine Minecraft's usefulness for planning engagement, but they had different opinions about the extent of this usefulness.

Five key findings will be discussed in this paper.

1. Minecraft as a Communication tool

2. Minecraft and Trust

3. The Place of Play in Planning

4. Online does Not Mean Accessible

5. The Most Promising Applications of Minecraft for Planning Engagement 


\section{Minecraft as a Communication Tool}

All respondents in this study recognized that the success of a public engagement initiative often hinges on the planners' ability to communicate effectively with the public. A theme that emerged from the interviews was that communication — the successful dissemination of information or a thought process to the public —is crucial, whether the ultimate goal of the engagement is to convey information, or to inform public feedback. The purpose of the engagement determines which strategies and tools are appropriate for facilitating communication, and which challenges must be met in order to communicate effectively. All respondents had some experience with both face-toface and digital communication tools. They had used digital tools to achieve different engagement goals, and with varying levels of success. As one respondent put it, you need to use "the right tools at the right time." Respondents reported some factors relevant to tool appropriateness, including the size and scope of the engagement, the demographics of desired participants, the type of response those participants were being asked to provide, and the degree of public empowerment.

A theme that emerged from the interviews was that face-to-face discussions ${ }^{16}$, if properly structured, could be more effective than digital interactions when the purpose of an engagement is to obtain detailed feedback from the public, or to achieve understanding between community members. According to five interviewees, face-to-face methods could be necessary if success in the engagement depends upon discovering the reasons for peoples' opinions. In-person discussion allows one to "get to the root of objection...much easier." One respondent described how an extended in-person conversation can reveal points of agreement where they may not have previously been apparent; discussion could reveal that "I may not agree with your conclusion but I have no issue with your thinking."

Three respondents did not dwell on the value of in-person discussion, and found there to be no problem collecting feedback from the public using an online tool as part of a larger discussion. Two of these interviewees did not make a strong distinction between discussion and obtaining feedback. They also did not feel that there was a difference in quality between information obtained in-person and online. One of these respondents suggested that the quality of public feedback seems to depend more on the individual's level of engagement, than the tool. Only one respondent felt that there were good online tools (such as idea managers) that could not only facilitate discussion, but might also produce superior results to in-person methods. This interviewee argued that because

\footnotetext{
${ }^{16}$ Not all respondents specified the scale and format of the most effective face-to-face discussion, although several mentioned that large meetings that were run by a single speaker were not typically effective. Several respondents felt that smaller groups - like roundtables - were more effective.
} 
online tools allow people time to think about the issues and form a considered opinion, online responses could be more thoughtful and informed than those offered at a public meeting ${ }^{17}$.

However, the other respondents felt that achieving in-depth understanding could be difficult in an online context. One respondent explained that the appropriateness of online tools can depend upon the depth of the feedback required: "if I'm just running an idea up the flagpole I can send out an online survey... If I want people to kind of wrap their minds around something and give us, really, their creative thoughts about something, I want to have a discussion." This respondent was aware of online tools that are designed to facilitate conversations (such as idea managers), but felt that conducting such an online discussion could be difficult because of the challenges of moderating these discussions, among other issues.

Another problem associated with online responses also emerged from the interviews. This problem, which is associated with asynchronous responses in particular, is that members of the public, when commenting through social media, a web page, email, or an online survey, can make short statements that sound definitive but may actually be part of a more complex perspective. It can be hard to recognize this perspective in an online context partly because of the way email, web site comments, or digital survey tools tend to be used: usually, the members of the public who respond using these methods are not asked follow-up questions ${ }^{18}$.

Interviewees also suggested that people are more likely to be antagonistic and intolerant when commenting through electronic means. In a face-to-face situation, social norms help ensure that behaviour is more thoughtful and measured. However, even when people respond politely, one respondent found that much digital feedback is unhelpful: it is "just noise" that "I can't take ... and [use to] make the project better." When online comments are shallow and unhelpful, it is often because of a failure of communication. Either planners have not been able to communicate what they to know, or the public has not been able to communicate the relevance of their comments for the project, ${ }^{19}$ or both. This failure of communication could be caused by many things, including an ineffective tool or poorly written questions.

The key informants for this project described the problem of communicating complex planning ideas to the public as a fundamental challenge for planners. Respondents recognized that planners were trained to consider

\footnotetext{
17 This respondent also stated, however, that the same effect could be achieved if online tools were used to provide information to the public in advance of a public meeting.

${ }^{18}$ If the feedback is anonymous, it may well be impossible to ask follow-up questions.

${ }^{19}$ Several respondents spoke about the importance of appropriately framing an engagement in order to facilitate communication. This is especially important when the engagement is being conducted remotely: "you have to ask the right questions you have to set the right atmosphere."
} 
specific, technical information and that it was difficult to communicate this information to a public untrained in planning concepts and methods. They must, as one respondent said, "demonstrate their wisdom-what it is, how they take all of this information and use it to inform decisions." This respondent thought that planners are not consistently able to communicate complex information in an accessible way: “That's a very particular skill that I'm not sure the profession as a whole — there are planners that are good at it — but the profession as a whole, I would say, probably has some work to do to make that better." Some respondents suggested that planners can address this problem by working with professional engagement facilitators, whose job it is to bridge the communication gap between planners and the public.

The traditional public meeting was given as an example of how planners can fail to communicate effectively with the public. One respondent described these meetings as long and complex, and said that presenters at these meetings tend to use confusing technical language. Another respondent suggested that long, formal town hall meetings continue to be held - despite the fact that they tend to be a difficult environment within which to communicate with the public — because not all administrators and municipal clients understand the value of engagement and, therefore, do not push for more effective methods.

A theme that ran through the key informant interviews is that planners can use visualization tools to better communicate with the public. These tools, whether physical or digital, can help the public understand difficult planning ideas. One respondent acknowledged the need for a variety of engagement techniques, including visual representations, because "people think differently, approach problem-solving differently." If well made, visualizations can communicate complex ideas and avoid abstract, technical language. One interviewee identified the value of non-text communication for removing "barriers to participation." Another respondent agreed, suggesting that visual representations were one way to address the communication challenges that planners face in a culturally and linguistically diverse city: planners "should be able to visually represent what we're trying to say to make it more accessible to everyone," including people with different learning styles and language skills. Effective images can both convey information, thus ensuring that public feedback will be informed and useful, and spark conversation. Even imperfect representations were described as important conversation starters by one interviewee. However, two respondents recognized that some visual tools can be difficult to make sense of: these respondents acknowledged that some visual aids_-like maps_-required a spatial literacy that members of the public do not always have.

Three dimensional representations were described in the interviews as useful for communicating information to the public about urban spaces, as well as facilitating discussion about those spaces. One respondent 
said that "3-D visualization or 3-D conceptualization is helpful in whatever form it is: foam core, or Lego" or digital representations using CAD modelling or SketchUp drawings. While digital 3-D models were described as useful, respondents mentioned several ways in which they could be better, including the time and expense associated with producing them, the difficulty of representing the context surrounding an area or building of study, and the difficulty of easily altering models once they had been constructed ${ }^{20}$.

The respondents agreed that Minecraft could, in certain situations, be a useful tool with which planners could represent urban spaces and, in so doing, communicate with the public. Planners could construct a model in Minecraft, and then allow the public to walk through it, or show them a fly-through. The interviewees recognized that Minecraft has several beneficial qualities as a visual representation tool. First, the Minecraft world is three dimensional. Minecraft players walk through three dimensional spaces and can get a sense for the scale of and relationship between different aspects of the space. One respondent felt that Minecraft could be useful because players could take different "vantage point[s] from all different places" around the site of interest. The ability to walk through the 3-D model would allow a member of the public to experience a site from multiple perspectives. Another respondent felt that Minecraft could be a effective way to "show changes in space over time" and visualize "impacts before anything goes forward."

The ease with which Minecraft's three dimensional representations can be constructed and changed in real time is another advantage of this game ${ }^{21}$. One respondent acknowledged that, while three dimensional models are useful, they tend to be expensive, because they require time and expertise to construct. This is a particular disadvantage if a project is on a tight timeline. Even if the expertise to construct a 3-D model exists in-house--for instance, a staff member may be able to model a building in SketchUp — it can still be time-consuming, and changes cannot be made quickly. Also, as one interviewee pointed out, SketchUp models do not usually include context, such as buildings around the site in question. SketchUp would not typically be used to draw a large portion of the city, for instance. One respondent had considered using SketchUp during a public meeting in order to communicate ideas as a discussion was taking place, but had never actually tried it because of the difficulty of providing context.

Unlike these other modelling programs, Minecraft allows users to quickly construct a 3-D representation of a space, including the elements that surround that space. Users can also easily make changes to that representation in order to show options or explain a principle. Further, a single Minecraft world can contain multiple models of the

\footnotetext{
${ }^{20}$ Another criticism - that 3-D representations often fail to direct audience attention to the appropriate aspects of the project early on in the project - will be discussed in the next section.

${ }^{21}$ Applications like WorldEdit and MCEdit make the process of building in Minecraft even faster. These programs allow players to quickly add or change large numbers of blocks in a Minecraft world.
} 
same site, so that community members can consider and compare options. One respondent suggested that offering choice through multiple 3-D models could help planners "isolate those elements of their knowledge that they're applying to make a decision and communicate that" to the public. Ultimately, these qualities could help planners introduce the public to a project, communicate the basic elements of that project (such as massing and density), and put early plans in a context: "Something like this could contextualize whatever it is [that] is changing and [give] people more of an idea of what's happening." The simple graphics and straightforward gameplay make Minecraft an accessible way to convey information to the public and ensure that the feedback they receive as a result is informed and useful. 


\section{Minecraft and Trust}

One issue that emerged out of the interviews conducted for this study is that planners often engage a public that is distrustful of planning engagement processes. For example, one respondent expressed frustration at the huge amount of time that planners spend doing public engagement and acknowledged that this is partly necessary because planners do not always have the public's "trust and understanding." The interviews done for this study suggest that engagement design could help offset this problem. When planners properly frame a discussion or information gathering process, they can both ensure that public feedback is informed, and build public trust in that process.

In the interviews, two factors were strongly associated with the credibility of an engagement process: clarity about the purpose of the engagement, and about which decisions are "open for influence." One interviewee summarized this point, saying that building trust depends on being "frank with people about what we're asking, what role you're asking them to play and about who's making the decision"22. It is important to communicate the purpose of the engagement so that the public understands that the process is meaningful, and that planners are reaching out not "just because it's a box we have to check off in the process." The danger of engaging the public when a decision is not "open for influence" is that "it just discourages their confidence because they talked a lot and nothing happened. There should be no pretence that something is going to happen.... You can talk, — just know that it's a dinner party. Don't pretend it's public policy." If there is confusion on this point, the public can become both frustrated and "suspicious of the utility of the exercise."

In the interviews, discussions around trust occasionally intersected with comments about the strengths and weaknesses of particular visualization tools. Several respondents were torn about 3-D models, for example, because while they are very useful, they are also problematic. Some models give the impression of completion or truthful, accurate representation when they are, in fact, intended to communicate a general sense of massing more than a finished plan. A massing model can appear to be the finished design for a future state: "it gives the impression that [the] model will be what the building looks like, but that's not true." This can be "hugely problematic," because "people get quite offended" and scared. Members of the public do not understand that "there's a significant degree of uncertainty in planning" and that a rendering does not predict a definite future.

\footnotetext{
${ }^{22}$ Another respondent explained the same principle in a slightly different way: planners need to tell the public "exactly what the objective is, exactly why we're engaging the public...[and being] genuine with the public about the scope of the engagement."
} 
Also, one respondent found that a professional, polished-looking rendering undermines the public's sense of purpose in the engagement: "for some people, it scares them when they see something really fully rendered... [They can think,] 'well this is done so why am I here? You already made this decision'.” In this situation, another respondent said, people can feel tricked "by the fact that you've taken them through this sort of elaborate process for the fun of it, as opposed to because you're really going to listen to them."

Another problem with renderings, as well as other kinds of visualizations, like photomontages, is the danger of misrepresentation. There was a tension apparent in the interviews: on the one hand, respondents recognized that visualizations provided a "wow effect" and could help do a "sell job" in order to inspire public buyin. But, on the other hand, they recognized that dishonest representations could breed public skepticism about visual representations and undermine public trust in the process. One respondent felt that this was a valid concern: "there's always a danger when we visualize something that we're misrepresenting potentially what the outcome might be." Another respondent concurred: "I think we can misrepresent things very fast." One interviewee felt that planners or engagement professionals had to be vigilant in order to ensure that they are not "promising things... that aren't necessarily realistic." This respondent explained that this vigilance was a part of their professional practice when working with images: "We try and be very careful that we're not just squishing a road to put a bike lane in, so the actual dimension being reflected is proportionate and honest." Professionals must strive for a way to represent what is known and not known, what is possible and not possible. When misrepresentation occurs, it renders the engagement less useful, and it breeds cynicism in the public. One respondent, in fact, had noticed a tendency in many members of the public to not "trust images." When presented with a rendering or a photomontage, they would say "well that's not really how it would look."

The problem of misrepresentation would seem to also apply to Minecraft models, although in a different way than it would to an AutoCAD rendering or a photomontage. Minecraft models are, arguably, even more unrealistic than other renderings, such as those constructed using SketchUp and AutoCAD. There are very few urban spaces that could be accurately represented using a Minecraft model, mostly because all elements of the Minecraft world are in cube form. There are no curves in Minecraft and no angles other than right angles ${ }^{23}$. As a result, there are limits to how detailed and accurate Minecraft models can be. Considering the public's skepticism about renderings, Minecraft might seem, at first glance, to be unsuited for planning engagement.

${ }^{23}$ However, there is a Minecraft mod called SuperSlopes that adapts the game so that sloped blocks are available to players. 
Surprisingly, the great majority of respondents in this study were unconcerned about the "blockiness" of the Minecraft world. Only two respondents found the game's coarse grain to be problematic: one respondent felt that the blocks restricted design creativity, and another felt that, in some infrastructure planning situations, accuracy in measurement was necessary even at a visioning stage ${ }^{24}$. This second respondent also felt that members of the public might have a hard time accepting an abstracted representation of spaces that are familiar to them. The other respondents, however, could imagine the usefulness of this game, despite (and partly because of) its low-resolution, stylized graphics.

Respondents suggested that, early on in the process of consultation, Minecraft's lack of accuracy could be more of a benefit than a drawback. Unlike more realistic renderings, Minecraft could not give a false impression of truth or accuracy. Any structure represented in this game is obviously unrealistic. Its cartoonish graphics could accomplish what more professional modelling programs can not. Minecraft could communicate the uncertain, unfinished nature of a model at an early stage: "People won't take it to be an exact representation..., but just an exploration of the possibilities." As a result, Minecraft representations could help establish the purpose of the engagement.

Early on in a planning process, the simplicity of a Minecraft model could also focus public attention appropriately — on an area's general features, such as massing and height. Whereas in an architectural rendering, people can get "distract[ed]" by details, Minecraft is "at a high-level. But still specific in a way. You focus on the bigger details. Because in any project the little things will always have to be worked out in more depth. [Minecraft] would be useful ... to start dialogue or to keep that dialogue going." Another respondent agreed that Minecraft provides enough detail, but not too much: 'it doesn't pretend to be an architectural rendering. It doesn't pretend, but it's kind of enough distinction that you can say, 'Oh yeah, I can get that."' The level of detail in Minecraft could be useful to start conversations and "get a sense for what people are interested in." Then, as the process continued, other visualization tools could be used to construct more specific, detailed representations of proposals or plans. One respondent felt that including a detailed representation early on in a planning process could be not only distracting, but also dishonest, because

\footnotetext{
${ }^{24} \mathrm{~A}$ third respondent identified an issue related to the blockiness of the game that could affect its ability to empower the public. The game's blockiness could be a problem if the public produced a Minecraft model, while a planner produced a more professional-looking model. The discrepancy between apparent competence and legitimacy could damage the public's belief in the value of their participation. This respondent suggested that engagement design could solve this problem. For instance, the public might be empowered if the planner were to work collaboratively with the public on the Minecraft model and articulate its usefulness.
} 
unless there's been all the work done and a commitment to the rendering, the design work at that level of detail (which is hugely far down in the process, and when you get to site plan you're not necessarily even there) then it's misrepresentative of what might actually be there.

Minecraft's lack of detail, and limited number of choices for constructing urban spaces, may also facilitate creativity in an interactive ${ }^{25}$ engagement initiative. One respondent explained that "[h]aving too many possibilities makes it too difficult to figure out what you're trying to build... creativity is built out of having constraints. You need to be creative when you have limitations.... I feel [that Minecraft,] being so blocky and being limited makes it a lot easier" to be creative. Another interviewee found Minecraft to have an "interesting combination of not-fullyformed—so, 'cartoony'—but allowing a huge pallet for creativity." One theme that emerged from the interviews was that a creative, interactive tool like Minecraft could allow members of the public to express their ideas in an interactive, creative way and, as a result, help interest them in an engagement process: "tools like visioning and being creative [are] all really helpful [for] getting people engaged." Of course, it is possible that people may not be interested in expressing their opinions through a video game. In evaluating the usefulness of Minecraft for planning engagement, it is important to consider its possible acceptance as a legitimate tool by both planners and the public.

\footnotetext{
25 The definition of "interactive" changed from one respondent to the next. Some respondents considered "interactive" to mean that the public were given the ability to personally control an image or representation (using blocks, for instance). However, one interviewee considered a project in which members of the public provided suggestions that a modeller would then use to construct a model for them, to be interactive.
} 


\section{The Place of Play in Planning}

Much of the literature that discusses video games and civic engagement suggests that games can provide an immersive space for civic learning and that they have the ability to motivate and inspire people (Gordon and Baldwin-Philippi 2014). This research study will not add to planners' understanding about how this takes place, but it will reflect on the ways in which planners and civic engagement professionals have used elements of play in their practice, and their sense of the legitimacy of games as an engagement tool. Also, this section will discuss some of the issues surrounding the design of a Minecraft engagement process. This section, unlike the previous two, discusses Minecraft as a true interactive, gaming experience. The previous two sections, which chiefly discussed Minecraft's potential as a visualization tool, did not fully address the interactivity of the game. These sections focused primarily on the opportunity to "playfully" walk, in avatar form, through a 3-D model. This section will discuss the implications of allowing the public to construct and alter plans for urban change. It will also consider why planners would encourage the public to interact with a model (or build one) in the Minecraft world, whether or not a game would be an obstacle or an advantage in a planning situation, and the different ways in which the game could be used (single- or multi-player, remote or in a central location, with constraints or not).

The interviews conducted for this study revealed the popularity of interactive and game-like activities for engagement. Some of these activities, such as building with blocks or Lego, and constructing models, were used by respondents for in-person engagement. Others, such as MetroQuest, were used for online engagement. The interviewees were, overall, more positive about the in-person games than the online ones. They acknowledged the benefits of tactile manipulation of material in order to express and learn about planning ideas. Physical interactivity was described as stimulating interest and creativity, and creating a positive feeling about the process. The online activities were less obviously successful. In some instances, online tools were believed to generate public interest and produce valid data. In other instances, there was uncertainty about how much understanding people had about what their adjustments to an interactive tool actually meant.

Another problem around digital games is their lack of adaptability. One respondent spoke about wanting to use StreetMix at a public meeting. StreetMix is an interactive web application that allows people to change the width and position of various elements on a street ${ }^{26}$ (i.e. bike lanes, bus lanes, sidewalks, etc). This respondent did not ultimately use the application, however, because it was not able to do everything that the team needed. As a result, they printed all necessary street elements on paper and did an analog version of the exercise at a meeting.

\footnotetext{
${ }^{26}$ This is not actually a game, but it is interactive, and has game-like feel to it.
} 
Games and interactive tools_— both analogue and digital—were used by respondents for several different purposes. These purposes include outreach, education, inspiring creative responses to a planning issue, and collecting feedback. One respondent had used Lego for outreach and promotional purposes. This situation was described as successful; however, this is not surprising, since its objectives were modest. The goals of this initiative were to attract children to the game in order to increase their (and, possibly, their parents') general interest in citybuilding, and to build awareness of a web site. In other words, this initiative was not intended to produce measurable results.

Analogue game-like activities used for education were also described as successful. These activities involved using blocks or Lego to facilitate a conversation about a specific planning issue, such as density. Sometimes, the purpose was not only education, but "also to get a sense of what people would actually want.” All those who had used this kind of strategy felt that it was well-received by the public. The interactive, tactile nature of physical model building was described as useful partly because it is a "creative act." One respondent explained that "there's real value in the tangibility and the face-to-face [process of] building something and using it as a way of communicating and having a conversation about what matters."

Some respondents had also used online interactive tools like MetroQuest to obtain feedback from the public $^{27}$. These were described with more ambivalence. For instance, one respondent, who had used such a tool more than once, felt that it was more successful in one case than the other. The more successful application had an element of fun, which the respondent described as "important." The less successful application was less fun, and fewer people had used the tool. There were other factors that likely contributed, however; the content in the lesssuccessful initiative was more complex than the more successful one. The respondent recognized that firm conclusions could not be drawn, but felt that the success of the first initiative was related to "the simplicity of the exercise, and it's a bit fun and it's playful. I think that probably contributed to how much uptake we had."

The ambivalence about online interactive tools may be related to the fact that planners and engagement professionals lack information about how the public thinks about and responds to these activities. Planners know how many people use these applications, but they do not know how seriously people treat them. This interpretive distance is troubling to some planners, and raises doubts about the usefulness of the data obtained through the online tool. What does it mean? One respondent had no qualms about the usefulness of the data obtained through interactive online tools, but recognized that getting good results depends on asking good questions. Reflecting on a

\footnotetext{
${ }^{27}$ MetroQuest is discussed in this section because it can have game-like, and fun, elements. Also, when asked about
} game-like tools, some respondents identified MetroQuest as fitting this description. 
particular application of MetroQuest, another respondent wondered if the participants had taken it seriously and whether they were thoughtful in providing responses or if they had participated because it was "fun to push buttons." This respondent emphasized the need to ensure that the game facilitates the collection of informed feedback, that "there's learning and thinking involved." The data from this exercise would only be useful if the people who used this application were thoughtful about their activities.

It is unclear why respondents were less certain about the value of online interactive tools. It may be that their impressions were formed by the nature of the interactive tool itself, specific things about the consultations they had conducted, or the interpretive and framing challenges associated with remote engagement. Clearly, attitudes towards engagement techniques affect the way in which they are used (or are likely to be used) by planners and the public. The openness of planners and the public to playing a game as a means of providing feedback or having a discussion about urban land use is an important part of assessing Minecraft's potential as an engagement tool.

The results of this study indicate that, in some situations, games are considered to be legitimate tools. For instance, most respondents felt that the Lego and other block tools were well-received and accepted by planners and the public. This attitude was not unanimous: one interviewee felt that when this kind of tool was used for outreach, some people were accepting, while others "had a very dismissive attitude." This respondent admitted "I'm not sure what it does accomplish." When used in more targeted ways, to describe a concept or inform a specific discussion, Lego and other block tools were only ever described in positive terms. Respondents called these tools "accessible," and did not feel the public was resistant to or dismissive of them. MetroQuest was also widely accepted as a legitimate tool, but because it is not truly a game, and only has some game-like qualities, it is difficult to know how to analyze the respondents' characterizations.

The interviewees were asked whether or not they felt planners would be open to using Minecraft for planning engagement. The interviewees were reluctant to speculate, but many of them thought that "planners would get it." A few respondents did admit the possibility that some planners might be dismissive of the game as a "crude tool." One respondent felt that planners may not take the feedback seriously—until it had been used for a few years and its usefulness had been demonstrated. Two other possible obstacles that were mentioned were planners' unwillingness to give up control to the public, and their resistance to simplifying complex planning concepts for the Minecraft context. Also, because "planners have a huge pressure on them to appear serious," the case for the game's usefulness would have to be convincing and articulate.

When respondents were asked whether they thought the public would accept Minecraft as a legitimate tool in an engagement situation, many agreed that some people would have no use for it because "[t]here will be sour 
apples or nay-sayers who [take issue with] really the full range of things." In the case of a digital game like Minecraft, age was presumed to influence a person's belief in the game's legitimacy. Respondents who commented on this issue assumed that the people who would be interested in playing the game as part of an engagement process would come from a younger demographic. As such, they would likely be younger than most of the people who currently participate in planning engagement processes. Speaking of in-person engagement, one respondent acknowledged that "the turnout tends to be an older demographic." Another respondent assumed that the people who most commonly attend engagement initiatives would not be attracted to the game. Several of the informant cohort recognized that these "typical participants" are not "representative of the population."

Interestingly, all respondents who spoke to this point were unbothered by the fact that Minecraft may not appeal to the people that most commonly attend planning meetings. One respondent felt that Minecraft could be useful because current engagement processes were already effective at attracting these people, and were less successful at convincing other kinds of people to participate: "it would't be very useful in helping us engage the typical people that we already engage.... But that's fine.... That's one reason you might use it. It might help us engage other people. It's not going to appeal to everyone, or even most people. But that's fine.” Attracting a wide range of people to engagement processes requires a great deal of thought and effort. One respondent spoke about the need to set "as few barriers to participation as possible," and to use diverse engagement tools in order to encourage participation. Respondents felt that different tools could reach different people, particularly when they are tailored for a specific demographic. One respondent explained that Minecraft might be useful for this reason: planners need to "broaden [their] toolbox as much as possible to engage as many people as possible and not every tool is going to be useful in every situation.... So I don't think that the fact that some people might find [Minecraft] to be not serious enough or whatever — trite—I don't think that's a reason to avoid it."

Assuming that there is a demographic of people who would be open to using Minecraft as an engagement tool, planners would still have to demonstrate the value of the game: "Members of the public, often, they need to be persuaded that playing a game would be helpful... So if you persuade them, then you can do it. You have to demonstrate why it's going to help everybody." Having a purpose for the game beyond just attracting people to the engagement situation was important for some interviewees. One respondent recognized that, while a game might be used for its novelty and "because [it is] interesting and fun," it should be used to address the more pressing challenge of engagement, which is to establish "a trust factor" and a belief in the value of the exercise.

In order for a game like Minecraft to be worthwhile to planners as a way to collect feedback, achieve understanding, or generate new ideas (and not just as an outreach or promotional tool), it would have to produce 
results that could be explained and analyzed: it would have to produce good data. Three informants identified the importance of being able to interpret the public's construction or manipulation of a model. If a member of the public built something in Minecraft, that structure might represent an expression of many separate opinions about the space on which they were building. It might be difficult for a planner to, after the fact, look at the Minecraft build and extrapolate those opinions. The degree of interpretive difficulty depends substantially on the context within which the build occurs. If the Minecraft player is in a room with a planner and other players, there could be a conversation around what they have done in the game. For example, two respondents discussed the possibility of having a session preceding or following a public meeting in which the public could use Minecraft to explore the ideas presented in the meeting. In this kind of context, Minecraft may also have potential as an education tool. Planners could use the game to teach the public about planning principles and problems. One interviewee suggested that the public could experiment with density in Minecraft, and that this interaction could help planners communicate the benefits of intensification. In this situation, the public's level of understanding would be clear to the facilitator.

In a remote, online Minecraft initiative, it would also be possible to gauge participants' comprehension and understand their opinions, depending on how the initiative is structured. If a remote build is part of a collaborative process with other players, those players would communicate with each other in order to think about and plan the goals of their build. This communication could happen in advance, or while playing Minecraft in an on-screen chat. The players' ideas could then be communicated back to planners. Or, as two respondents suggested, an online session could include a facilitator who could walk participants through a process or introduce them to key issues. If, however, players play alone, remotely, and leave no indication of their thought process, it would be difficult to extrapolate the principles that inspired their gameplay.

Four interviewees recognized that a Minecraft engagement exercise would be more useful if it recognized the constraints within which urban change occurs. One respondent gave an example of an area where there is “zoning in place already that says you cannot go below three stories, so everything is three stories to start with.... I can imagine if it's given into the hands of residents or people who don't understand this planning context," they may not comprehend or respect the current zoning restrictions. Other respondents discussed the need to have a system that governs available options in a Minecraft game, or, at least, an understanding of the ramifications of the player's decisions: "The ability to manipulate it would be great, but only if that manipulation was informed by the consequences of what people were doing. So, are you aware that, by making this move, you would have to pay an extra $\$ 200,000$ in taxes a year? Are you aware that by making this move, you're building something that, right now, 
the market can't bear?" Building conditions like these into a Minecraft context is possible, but would require some thought and would be an implementation challenge.

Minecraft will only be used to interact and exchange ideas with the public if it offers some kind of value to the process. Respondents mentioned many possible kinds of value that the game could add, including encouraging creativity, capturing participants' attention for a longer period of time, educating the public about planning concepts and site-specific challenges, and helping the public provide more informed, thoughtful feedback. Depending on how the Minecraft engagement was structured, any (or all) of these could be achieved. Clearly, more research is needed to develop interactions that accomplish these goals. 


\section{Online does not mean Accessible}

One of the conundrums that emerged from the interviews conducted for this project was the difficulty of taking advantage of the elements of Minecraft that are the most potentially powerful for planning engagement. As the first two sections of this study's key findings describe, Minecraft is an unusual, and potentially useful, 3-D visualization tool. It is much faster and easier to build a 3-D model of a space in Minecraft than it is in any other software currently in use today. However, the ability to quickly and easily build a 3-D model might transform engagement more for planners than for the public. Of course, it could be a beneficial experience for community members to be able to walk through the Minecraft world as an avatar. It could also be useful for the public to visualize a particular area in its context by watching an internet video of an avatar walking or flying through a Minecraft world.

However, Minecraft could offer the public so much more than this when used in a more interactive waymore learning, more creativity, and more immersion. The public could learn about setbacks and floor-area ratios in a Minecraft world. They could experiment with different ways to add density along one of the City of Toronto's designated Avenues. They could investigate different building sizes and shapes for a redevelopment. However, structuring an engagement to facilitate this more ambitious kind of exercise has many challenges.

The difficulty of giving the public an opportunity to build on or change an urban space in Minecraft depends on the context within which the gameplay occurs. Two factors are particularly important: if the player is playing remotely or in a central location as part of a meeting or workshop, and if the player is playing in single- or multi-player mode.

If the public is given an opportunity to play Minecraft at a public meeting or workshop of some kind, it would be much easier for planners to frame the engagement and interpret what members of the public are doing. It would be easy to allow members of the public to play alone, but it would also be easy to set up and manage a multiplayer experience. Players could play simultaneously on multiple computers that were set up for that purpose and logged into the same server on a local area network (which is easy to do in Minecraft). An idea that came out of the interviews is that collaborative play in Minecraft might be more beneficial than individual gameplay. One interviewee thought that Minecraft would be better able to create a positive emotional tone in an engagement if it were constructed as a "collective exercise"- either people working together at the same time, or working on different parts of the same project in their own time. In this context, any member of the public who comes to a public meeting to work with a team could gain all the wider benefits that Minecraft offers: creativity, education, and 
the ability to express detailed opinions about the issue at hand. The main challenges would be providing enough time for participants to play, having enough copies of the game, and procuring the necessary equipment ${ }^{28}$.

However, because Minecraft can be played remotely, and because there is a large appetite for remote engagement tools, it would be ideal if people could experience these same benefits from their home computer. As one respondent put it, "the one advantage of doing something that is more computer-generated in terms of interaction is you could do it remotely." However, there are some logistical difficulties. The first, and most significant obstacle, is that, in order to play Minecraft, you need to create a (free) Mojang account and buy the game, which is around $\$ 30 \mathrm{CAD}$. Although many people already own the game, many more do not. Many people will not be able to afford this amount, and many others could be reluctant or unable to purchase and install a video game on their personal computers. The game could be provided through a publicly accessible computer at, for instance, a public library. However, if it was offered in this way, it could be difficult to keep track of who has participated. Another possible site of access is through schools. Many schools already have MinecraftEdu installed in their computer labs, so they could provide youth with a way to participate in an engagement process. For the general public, however, needing to purchase the game is a significant barrier.

Other difficulties associated with remote play include appropriately framing the engagement, setting its conditions using game design, and interpreting its outcomes. Planners could not be sure that players have read the introductory materials (or watched an introductory video) before playing. They also would have to think through how to set conditions, and which conditions to set, to make sure that the game was meaningful, and that it provided feedback that planners could use. As previously mentioned, it could be difficult to understand the meaning of community members' Minecraft decisions. There are ways to mitigate this problem ${ }^{29}$, but it would require research through, for instance, a pilot project.

Remote Minecraft play could also involve collaboration — there are many Minecraft players that regularly collaborate all over the world. However, planners would need to think through how to structure and inform that collaboration in the Minecraft world so that it would facilitate player creativity, immersion, and problem-solving in a positive environment.

\footnotetext{
${ }^{28}$ This may not be a prohibitive expense, depending on who (municipal planners or consultants) is organizing and running the meeting. As previously mentioned, there is a version of Minecraft that will run on the Raspberry Pi, which is a low cost, energy efficient computer. These machines can even run Minecraft servers.
}

${ }^{29}$ For instance, players could place signs next to their builds in Minecraft that explain what they have done and why. 


\section{The Most Promising Applications of Minecraft for Planning Engagement}

This research study has discussed four themes that emerged from the key informant interviews. In discussing these themes, this study has identified different reasons for using Minecraft for planning engagement, as well as the challenges associated with different applications of the game. During the interviews, respondents were also asked to reflect on whether Minecraft could be useful in three specific planning engagement situations. The situations presented to the interviewees include: facilitating communication around a Committee of Adjustment hearing, for a rezoning or redevelopment, and for an Official Plan review. The interviewees' comments on these situations, as well as the previous four themes, will inform this section, which outlines several possible applications of Minecraft.

Each of the three planning engagement situations attracted the support of some respondents. For the Committee of Adjustment level, some felt that having a way of visually showing optional ways of approaching a change to a property could help facilitate communication between neighbours or communication with the Committee: "how much easier would it be for someone to come and make a presentation to Committee of Adjustment having created their visualization and what they wanted — it would be so clear." It could also be useful to make changes to the model during a discussion: "And if you had a discussion what if we just lowered the wall you could just do it right away... I could see it would be really helpful for people ... who have problems visualizing." One respondent, however, made a convincing argument that Minecraft would likely not be appropriate to communicate changes on this scale because it may not have "the level of detail required for something that small."

When asked about antagonism around an application for a variance, and whether a game could help create a more positive atmosphere, three respondents felt that this was possible, but the others suspected that the game itself would not necessarily be able to shift the tone of the conversation ${ }^{30}$. The sense was that if a situation was already antagonistic, using a game to help people communicate was just as likely be to heighten the conflict as it would be to reduce it: using a game could "be experienced as a very offensive attempt to make something fun which is not." Two respondents mentioned that collaboration could be key to neutralizing antagonism through a game. If people were able to work collaboratively in Minecraft, it might be easier for them to work through their problems. This may be difficult to accomplish, however, because of the problem of "unequal access to [and knowledge of] technology." One respondent felt that unequal technical knowledge could be particularly problematic at the Committee of Adjustment level: "One neighbour might have a kid who could do this and the other neighbour can't."

\footnotetext{
${ }^{30}$ If the situation was not antagonistic, however, one respondent felt that using a game like Minecraft could help "insert some levity" and "spontaneity" into an engagement situation. Others agreed that it could be even easier to use a game like Minecraft for engagement in a situation that is exploratory or playful.
} 
The planning situations that seemed most promising for a Minecraft exercise, according to the respondents, were rezonings or redevelopments. In this context, Minecraft could provide a "sense of scale and size and use" as well as "proposed density and massing." There was some disagreement about whether Minecraft would be most useful on a site-by-site basis or for a larger area. One respondent felt the Minecraft does not provide enough detail to be useful on a individual site basis, mostly because of the game's lack of angles. Other respondents, however, felt that having a Minecraft model that not only showed a new development, but also showed the context around that development, could be very useful. One respondent felt that, specifically, Minecraft would not be useful for a large rezoning, because the nature of the rezoning (i.e. changing from outdoor to indoor storage or some such detail) may not be "tangible" enough to be demonstrated in the game. Several respondents mentioned that the game could be useful for a City of Toronto Avenue study or another project of a similar scale. One respondent said that it would be fascinating if, as part of an Avenue study, people could "build their own environments and help manipulate it and decide how they want it to look in the future."

When asked about using Minecraft for an Official Plan review engagement, the respondents were also generally positive, feeling that there was "potential to engage people in a creative imaginative way on a big scale." A Minecraft model could help illustrate how certain policies can effect change over time. However, one respondent worried that, at the city scale, the model could look more like a topographical map. At that scale, the respondent felt, a two-dimensional diagram might be better. For the same reason, two other respondents found it difficult to imagine the usefulness of Minecraft for a Regional government's Official Plan review. One respondent did suggest that a Minecraft model could focus on "stable areas versus areas of change, and Avenues, [and] employment areas.” This might be a necessary approach for the City of Toronto, in particular, because its Official Plan creates "an enabling policy" but does not include specific detail, like density numbers. One respondent said that other municipalities that include more detail in their official plan could use Minecraft to show where they are suggesting density to go, and suggest "three or four different ways for it to be achieved." Another interviewee suggested that the best use of the game might be to represent secondary plan areas. 


\section{Conclusion and Suggestions for Further Research}

Planners and engagement professionals were interviewed for this research study in order to reflect on the possible usefulness of Minecraft for planning engagement. These interviews indicated several ways in which Minecraft could help planners in their efforts to involve the public in land use planning processes. While this study provides insight into the utility of one digital engagement tool-Minecraft - it also reflects on some of the broader challenges associated with engaging the public using digital tools. It is useful to reflect on these challenges because, as one respondent explained, the use of digital tools is "pretty much a standard ask" in any engagement initiative; both municipalities and the public typically want digital tools to be a part of any such initiative. However, the interviewees also emphasized the many difficulties that come along with using the digital tools that are currently available today. These issues include ensuring an appropriate level of participant privacy, monitoring the engagement, reducing barriers to participation, designing a project that will meet the needs of planners and the public, and ensuring that the costs associated with using digital tools are reasonable and well-founded.

Despite these challenges, many interviewees expressed hope that a tool such as Minecraft could help them better accomplish the complex, challenging work of public engagement. These respondents were eager to consider the usefulness of a new digital tool, partly because it might help planners get away from the static nature of some traditional engagement practices, and partly because there are some things that planners have a hard time doing, like easily preparing effective and honest representations of an urban space that is undergoing change, or using an interactive tool to engage the public in a meaningful way. Something that became clear in the interviews was that, because the work of designing a Minecraft engagement project has not already been done, it would be difficult for a planning department or consultant to use Minecraft for engagement. It would be much easier for planners to use new digital tools like Minecraft if there was more research available to guide them.

Because the speed at which planning departments incorporate new technologies, and the speed at which those technologies change, are very different, practicing planners and engagement professionals would benefit if digital technologies were regularly assessed and tested for their applicability for planning engagement. Faced with budgetary limitations, complex engagement goals and staff that are only trained in the use of specific software packages, these professionals can not keep track of, or develop projects using, most digital tools that are currently available. The municipal and regional planners interviewed for this study recognized that new digital engagement tools had potential, but felt it was difficult to experiment with them because of budgetary and staffing limitations.

Urban planning departments in post-secondary institutions could help practicing planners and engagement professionals better integrate new technologies into their engagement processes. By making the evaluation and 
development of digital engagement tools a higher priority for research, these institutions could support and improve planning engagement. This research should occur at different scales_-from small studies (like this one) that evaluate the potential usefulness of existing tools, to pilot projects that explore specific applications of those tools, to labbased projects in which new tools are developed specifically for planning engagement purposes ${ }^{31}$.

The evaluation of digital engagement tools is partly important because information about these tools could help shift the conversation away from the tools themselves to more fundamental issues. One informant for this study felt that the abundance of digital tools tends to increase attention to the issue of how to engage people, and distract attention from why that engagement is taking place. If the applicability of digital tools was better understood, they could be more easily matched with specific engagement goals and, as a result, planners would have more time to think about the purpose and goals of engagement.

As this study makes clear, more research into Minecraft's applicability for planning engagement is warranted. This research would support municipalities or engagement consultancies that want to use games like Minecraft to facilitate a creative exchange of ideas with the public. Three suggestions for further research will be offered here.

The first of these suggestions comes directly out of the interviews conducted for this study. Many respondents in this study assumed that only a younger demographic would be interested in playing Minecraft. This assumption should tested in a research study. Such a study could evaluate the public's willingness to participate and would shed light on whether or not Minecraft is largely appropriate for certain demographics, or if its appeal is more widespread. The results of such a study would help planners decide which engagement initiatives would most benefit from using Minecraft. For instance, if Minecraft does appeal to a younger demographic, and if planners are planning an engagement initiative that would benefit from the participation of young people, planners might choose Minecraft as one of their engagement tools.

Pilot studies should also be conducted in order to test Minecraft's usefulness as an education and interactive visioning tool. Educational objectives could include teaching the public, through experimentation in a Minecraft world, about planning principles and concepts such as floor-area ratios, density, and zoning, among others. This study could also reflect on the advantages that Minecraft has over other analog block tools, including Lego.

${ }^{31}$ Of course, projects like these have already been done at some institutions. For instance, MetroQuest was developed through a public-private partnership between the University of British Columbia and Envision Sustainability Tools. Also, as previously mentioned, Emerson College's Engagement Game Lab has developed Community PlanIt, which has been used by several American municipalities for planning engagement. 
A more ambitious pilot would assess the usefulness of engaging the public in a Minecraft build as part of a visioning process. Such a study could present members of the public with a Minecraft world that depicts the larger context around the area in question and ask them to explore the possibilities and offer their own ideas about how the area should change. This study could compare results from an online initiative with one conducted as part of a workshop or meeting.

Of course, the onus is only not on post-secondary urban planning departments to research or incubate new technologies in order to help municipal planners and engagement professionals effectively use digital tools. Those professionals must also adapt to the changing context within which they practice. Some of the respondents in this study demonstrated a forward-looking, flexible attitude that is essential in the current context. Several respondents described their conviction that keeping up with new applications of digital technologies for engagement, and the discussions around these applications, was an important part of their job. This is a sound strategy: planners will be better equipped to use new technologies if they routinely seek out information about them, rather than waiting until pressured by decision-makers or the public to think about how new technologies can be incorporated into engagement practice.

Planners need to attend to the potential of digital tools for engagement processes because our society's collective assumptions about how people can and should exchange ideas about important social issues is changing. These tools are increasingly recognized as essential for public discourse. The Canadian Institute of Planners, in its "Statement of Values," identifies the need to foster meaningful public participation and to respect the diversity of that public ${ }^{32}$. The definition of "meaningful" public participation has clearly changed in recent years, along with our most common modes of communication. Now, more than ever before, "meaningful" participation is expected to occur digitally; citizens assume that they will be able to contribute to discussions around land-use planning using digital tools. However, despite the fact that digital methods are demanded by the public, and are often treated as indispensable communication tools, they do not always produce useful results or improve planning engagement outcomes. If we are to improve these outcomes, and resolve this discrepancy, we must strive to better understand our digital tools through research.

\footnotetext{
${ }^{32}$ Clearly, some digital tools, like Minecraft, could help reach some sectors of a diverse public because they may appeal to a younger demographic. Minecraft could also help meet the needs of those individuals who prefer, and better understand, spatial and visual representations over textual or auditory descriptions.
} 


\section{References}

Adams, Jeffrey. (2012) "Inquiry Learning? Try a Game" Teaching Boys at the Coal Face: Mining Key Pedagogical Approaches. Action Research Report 2012. International Boys' School Coalition. pp. 5-13.

Apostol, Ileana, Panayotis Antoniadis, and Tridib Banerjee, (2012). "Flânerie between Net and Place: Promises and Possibilities for Participation in Planning." Journal of Planning Education and Research. 33(1). p. 20-33.

Arnstein, S. (1969) "A ladder of citizen participation in the USA." Journal of the American Institute of Planners. 35. p. 216-224.

Ask, A., Hatakka, M. and Grönlund, Å., (2008). "The Örebro City Citizen-Oriented eGovernment Strategy.” International Journal of Electronic Government Research. 4(4), p. 69-88.

Bakker, Tom P. and Claes H. deVreese. (2011). "Good News for the Future? Young People, Internet Use, and Political Participation." Communication Research. 38(4). p. 451-470.

Bamberg, Jarkko. (2013). "Engaging the public with online discussion and spatial annotations: The generation and transformation of public knowledge." Planning Theory \& Practice. 14(1), pp. 39-56.

Batty, Michael, Andrew Crooks, Andrew Hudson-Smith, Richard Milton, Suchith Anand, Mike Jackson and Jeremy Morley. (2010). "Data mash-ups and the future of mapping." Technology \& Standards Watch (TechWatch) Retrieved at: http://www.jisc.ac.uk/media/documents/techwatch/jisctsw_10_01.pdf

Berdou, Evangelia. (2011) "Mediating Voices and Communicating Realities: Using information crowdsourcing tools, open data initiatives and digital media to support and protect the vulnerable and marginalised." Institute of Development Studies. Retrieved at: http://r4d.dfid.gov.uk/PDF/Outputs/Misc_InfoComm/ IDS_MediatingVoices_FinalReport.pdf

Bers, Marina Umaschi. (2010). "Let the Games Begin: Civic Playing on High-Tech Consoles.” Review of General Psychology. 14(2), pp. 147-153

Bleumers, Lizzy, Anissa All, Ilse Mariën, Dana Schurmans, Jan Van Looy, An Jacobs, Koen Willaert, Frederik de Grove, (2012). "State of Play of Digital Games for Empowerment and Inclusion: Review of the Literature and Empirical Cases." European Commission Joint Research Center. Review of General Psychology. 14(2), pp. 147-153

Blumberg, F.C., Almonte, D.E., Anthony, J.S., \& Hashimoto, N. (2013). "Serious Games: What are they? What do they do? Why should we play them?" In K.Dill (Ed.). Oxford Handbook of Media Psychology. (pp. 334 351). New York: Oxford University Press.

Brabham, Daren. C. (2009). "Crowdsourcing the Public Participation Process for Planning Projects" Planning Theory. 8(3). p. 242-262.

Branigan-Pipe, Zoe. (2013). "Community and Urban Planning — Project Based Learning and Minecraft." Pipedreams. Retrieved at: http://pipedreams-education.ca/2013/01/25/community-and-urban-planningproject-based-learning-and-minecraft/

Brail, Richard K. and Richard E. Klosterman, eds. (2001). Planning Support Systems: Integrating Geographic Information Systems, Models, and Visualization Tools. ESRI..

Bridgman, Rae. (2004). "Criteria for Best Practices in Building Child-Friendly Cities: Involving Young People in Urban Planning and Design." Canadian Journal of Urban Research. 13(2).

Bristow, Elliott. (2013). “Gaming in Education: Minecraft in Schools?” The EduBlogger. Retrieved at: http:// theedublogger.com/2013/11/21/gaming-in-education-minecraft-in-schools/

Brody, S.D., Godschalk, D.R. and Burby, R.J. (2003). "Mandating Citizen Participation in Plan Making: Six Strategic Planning Choices." Journal of the American Planning Association. 69(3): 245-64.

Brown, R.J. (2013) "Minecraft in the Classroom: Ep 5 Sustainable Living." The Second Perspective. Retrieved at: http://rjbrownauthor.edublogs.org/2013/08/17/minecraft-in-the-classroom-ep-5-sustainable-living/

Bryson, John M., Kathryn S. Quick, Carissa Schively Slotterback, and Barbara C. Crosby, (2012). "Designing Public Participation Processes." Public Administration Review. 73(1), pp. 23-34.

Burby, R.J. (2003). "Making Plans that Matter: Citizen Involvement and Government Action." Journal of the American Planning Association. 69(1): 33-49.

Canadian Institute of Planners. "Statement of Values and Code of Professional Practice." Retrieved at: http:// www.cip-icu.ca/_CMS/Files/Code\%20of\%20Professional\%20Practice.pdf

Conroy, M. M. \& Gordon, S. I. (2004). "Utility of interactive computer-based materials for enhancing public participation.” Journal of Environmental Planning \& Management. 47(1), pp. 19-33. 
Couldry N, Livingstone S and Markham T (2007). Media Consumption and Public Engagement. Basingstoke. UK, Intellect.

Creighton, J. L. (2005). The Public Participation Handbook: Making Better Decisions Through Citizen Involvement. San Francisco, CA: Jossey-Bass.

Cullingworth, J. Barry. (1984). "Canadian Planning and Public Participation.” Research Paper. Centre for Urban and Community Studies, University of Toronto.

Davies, Marsh. (2012) “The Future of Minecraft: what lies ahead for the all-conquering sandbox game?" PCGamer. Retrieved at: http://www.pcgamer.com/2012/11/11/the-future-of-minecraft/

Day, Laurie, Liz Sutton, and Sarah Jenkins. (2011). "Children and Young People's Participation in Planning and Regeneration: A final report to the ECORYs research programme 2010-11." Centre for Research in Social Policy. Retrieved at: http://www.uk.ecorys.com/pdfs/Ecorys\%20CRSP\%20Final\%20Report.pdf.

De Filippi, F. and R. Balbo. (2011). "Planning for real: ICT as a tool in urban regeneration." The Built \& Human Environment Review. 4(1). p. 67-73.

Desouza, Kevin C. and Akshay Bhagwatwar, (2012). "Citizen Apps to Solve Complex Urban Problems." Journal of Urban Technology. 19(3), p. 107- 136.

Elwood, S and Leszczynski A. (2010). "Privacy, reconsidered: New representations, data practices, and the geoweb." Geoforum 42: 5-16.

Evans-Cowley, Jennifer and Maria Manta Conroy. (2006). "The Growth of E-Government in Municipal Planning." Journal of Urban Technologies. 13(1), 81-107.

Evans-Cowley, Jennifer and Justin Hollander. (2010). "The New Generation of Public Participation: Internet-based Participation Tools." Planning Practice and Research. 25(3), 397-408.

Flyvbjerg, Bent. (1998). Rationality and Power. Chicago: University of Chicago Press.

Forester, J. (1989). Planning in the face of power. University of California Press, Berkeley, CA.

Foth, M., Forlano, L., Satchell, C., \& Gibbs, M. (Eds.), 2011. From Social Butterfly to Engaged Citizen: Urban Informatics, Social Media, Ubiquitous Computing, and Mobile Technology to Support Citizen Engagement. Cambridge, MA: MIT Press.

Fredericks, Joel and Marcus Foth. (2013). “Augmenting Public Participation: Enhancing Planning Outcomes through the Use of Social Media and Web 2.0." Australian Planner. 50(3), p. 244-256.

Garau, Chiara. (2012). "Focus on Citizens: Public Engagement with Online and Face-to-Face Participation-A Case Study." Future Internet. 4, 592-606.

Gee, J.P. (2007a). Good video games and good learning. New York: Peter Lang.

Gee. J.P. (2007b). What video games have to teach us about learning and literacy. New York: Palgrave Macmillan.

Goodspeed, Robert C. "Citizen Participation and the Internet in Urban Planning." Master of Community Planning Final Paper, University of Maryland. Retrieved at: http://ipg.org.ph/old/images/Files/patricip/goodspeedinternetparticipation.pdf

Gordon, Eric and Jessica Baldwin-Philippi. (2014). "Playful Civic Learning: Enabling Reflection and Later Trust in Game-based Public Participation." International Journal of Communication. 8, p. 759-786.

Gordon, Eric (2012). "Gaming City Planning: Community PlanIt in Detroit.” Knight Blog. Retrieved at: http:// www.knightfoundation.org/blogs/knightblog/2012/6/13/gaming-city-planning-community-planit-detroit/

Gordon, Eric, Steven Schirra, and Justin Hollander. (2011). “Immersive planning: a conceptual model for designing public participation with new technologies." Environment and Planning B. 38, pp 505-519.

Gurstein, M.B. (2011). “Open Data: Empowering the Empowered Or Effective Data use for Everyone?" First Monday. 16(2). SCOPUS. Retrieved at: http://firstmonday.org/ojs/index.php/fm/\%20article/view/ $3316 / 2764$

Hall, Joseph. (May 2013). "Minecraft game being hailed as teaching tool.” The Toronto Star. Retrieved at: http:// www.thestar.com/news/insight/2013/05/31/minecraft_game_being_hailed_as_teaching_tool.html

Haste, Helen. (2009). "What is 'competence' and how should education incorporate new technology's tools to generate 'competent civic agents"” The Curriculum Journal. 20(3), pp. 207-223.

Healey, P. (1997). Collaborative planning: shaping places in fragmented societies. Macmillan, Basingstoke.

Hibbard, M. and Lurie, S. (2000) "Saving Land but Losing Ground: Challenges to Community Planning in the Era of Participation." Journal of Planning Education and Research. 20(2): 187-95. 
Hollander, Justin B. (2011). "Approaching an Ideal: Using Technology to Apply Collaborative Rationality to Urban Planning Processes.” Planning Practice and Research.” 26(5). p. 587-596.

Horelli, Liisa and Mirkka Kaaja. (2002). "Opportunities and Constraints of 'Internet-Assisted Urban Planning' with Young People." Journal of Environmental Psychology. 22(1-2), pp 191-200). Retrieved at: http:// www.ucl.ac.uk/dpu-projects/drivers_urb_change/urb_infrastructure/pdf_city_planning/ Horelli_Liisa_Kaaja_Mirkka_2001_Internet_urban_planning.pdf

Hunter, Andrew, Stefan Steiniger, Beverly Sandalack, Steve Liang, Lina Kattan, Amer Shalaby, Francisco Alaniz Uribe, Coral Bliss-Taylor, Ryan Martinson, (2012). "PlanYourPlace: a geospatial infrastructure for sustainable community planning." Revue Internationale de Geomatique. 10. p. 1-10.

Innes, J. and David E. Booher (2005). "Living in the house of our predecessors: The demand for new institutions for public participation." Planning Theory and Practice. 6(3), p. 431-435.

Innes, Judith E. and David E. Booher. (2010). Planning with Complexity: An Introduction to Collaborative Rationality for Public Policy. New York: Routledge.

Innes, Judith E. and David E. Booher. (2000). "Public Participation in Planning: New Strategies for the 21st Century." Institute of Urban and Regional Development.

Innes, Judity E. and David E. Booher. (2004). "Reframing Public Participation: Strategies for the 21st Century." Planning Theory and Practice. 5(4), p. 419-436.

Ito, M., \& Bittanti, M. (2010). “Gaming.” In Ito, M., et al. (Eds.), Hanging Out, Messing Around, GeekingOut: Kids Living and Learning with New Media. Cambridge, MA: MIT Press.

Jenkins, H., Clinton, K., Purushotma, R., Robison, A. J., \& Weigel, M. (2006). Confronting the challenges of participatory culture: Media education for the 21st century. Chicago: MacArthur Foundation.

Kaboom, n.d. "Our Dream Playground." Retrieved at: http://ourdreamplayground.kaboom.org/

Kahne, Joseph, Ellen Middaugh, and Chris Evans, (2009). “The Civic Potential of Video Games.” The John D. and Catherine T. MacArthur Foundation Reports on Digital Media and Learning. Cambridge: MIT Press.

Kamensky, John M. “The Games of Government.” Governing. Retrieved at: http://www.governing.com/blogs/bfc/ col-video-games-local-government-public-services.html\#

Kubicek, Herbert. (2010). “The Potential of E-Participation in Urban Planning: A European Perspective.” Handbook of Research on E-Planning: ICTs for Urban Development and Monitoring. Ed by Carlos Nunes Silva.

Hoene, Christopher, Christopher Kingsley and Matthew Leighninger, (2013). Bright Spots in Community Engagement: Case Studies of U.S. Communities Creating Greater Civic Participation from the Bottom $U p$. National League of Cities. the Knight Foundation.

Kosterman, Richard E. (2001). "Planning Support Systems: A New Perspective on Computer-Aided Planning." Planning Support Systems: Integrating Geographic Information Systems, Models, and Visualization Tools. Eds. Richard E. Klosterman and Richard K. Brail. ESRI. p. 1-24.

Kolbitsch, J. and Maurer, H., 2006. "Transformation of the Web: How Emerging Communities Shape the Information we Consume.” Journal of Universal Computer Science. 12(2), 187- 213.

Lane, Marcus B. (2005). "Public Participation in Planning: An Intellectual History." Australian Geographer. 36:3, 283-299.

Lee, Peter and Georgios Theodoropoulos. (2012). "An Open Source Simulation-based Approach for Neighbourhood Spatial Planning Policy." Proceedings of the 2012 Winter Simulation Conference. Ed. by C. Laroque, J. Himmelspach, R. Pasupathy, O. Rose, and A.M. Uhrmacher.

Majury, Kris. (2013). "Building Norway in Minecraft with FME.” blog.safe. Retrieved at: http://blog.safe.com/ 2013/07/fmeevangelist118-2/

Mallan, Kerry, Marcus Foth, Ruth Greenaway, Greg T. Young (2010). "Serious Playground: Using Second Life to Engage High School Students in Urban Planning." Paper for the special issue on "Learning in Virtual Worlds" of the Journal of Learning, Media and Technology, Ed. by Jeremy Hunsinger and Aleks Krotoski.

Mandarano, Lynn, Mahbubur Meenar, and Christopher Steins. (2010). "Building Social Capital in the Digital Age of Civic Engagement." Journal of Planning Literature. 25(2), 123-135.

Manneh, Carl. (2011). "Minecraft empowers people to change their block." Retrieved at: http://mojang.com/ 2011/10/minecraft-empowers-people-to-change-their-block/ 
Manneh, Carl. (2012). “Mojang and UN present: Block by Block.” Retrieved at: http://mojang.com/2012/09/ mojang-and-un-presents-block-by-block/

McClarty, Katie Larsen. Aline Orr, Peter M. Frey, Robert P. Dolan Victoria Vassileva, and Aaron McVay. (2012). "A Literature Review of Gaming in Education." Pearson Research Network. Retrieved at: http:// researchnetwork.pearson.com/wp-content/uploads/Lit_Review_of_Gaming_in_Education.pdf

Mees, Paul and Jago Dodson, 2007. "Backtracking Auckland?: Technical and Communicative Reason in Metropolitan Transport Planning." International Planning Studies. 12(1), 35-53

MetroQuest. n.d. Retrieved from: metroquest.com

Ontario Ministry of Municipal Affairs and Housing. (2014). "Provincial Policy Statement, 2014." Retrieved from: http://www.mah.gov.on.ca/AssetFactory.aspx?did=10463

Ordnance Survey. (2013). Retrieved from: http://www.ordnancesurvey.co.uk/blog/2013/09/minecraft-creating-amap-of-great-britain/

Parsons, Jennifer A. (2008). “Key Informant.” Encyclopedia of Survey Research Methods. Ed. by Paul J. Lavrakas. Retrieved at: http://dx.doi.org/10.4135/9781412963947.n260

Planning Act, R.S.O. 1990, c. P.13. Retrieved from: https://www.e-laws.gov.on.ca/html/statutes/english/ elaws_statutes_90p13_e.htm

Raphael, C. , Bachen, C. and Kathleen-M Lynn, Jessica Baldwin-Philippi, and Kristen A. McKee, (2010). "Games for Civic Learning: A Conceptual Framework and Agenda for Research and Design." Games and Culture. 5(2), pp. 199-235.

Sandercock, L. (ed.) (1998). Towards cosmopolis: planning for multicultural cities. Wiley, Chichester.

Sandercock, L. (2005). "The democratization of planning: Elusive or illusory?" Planning Theory \& Practice. 6 (4), 437-441.

Sasaki, 2012. “Innovative Planning: Game-Changing Engagement.” Retrieved at: http://www.sasaki.com/blog/view/ $165 /$

Senior, Tom. (2012). "Minecraft UN Block By Block project to help young people redesign their neighbourhoods" PCGamer. Retrieved at: http://www.pcgamer.com/2012/09/05/minecraft-un-block-by-block-project-tohelp-young-people-redesign-their-neighbourhoods/

Shah, Dhavan, Nojin Kwak, and R. Lance Holdert. 2001. "'Connecting" and 'Disconnecting" with civic life: Patterns of Internet use and the production of social capital." Political Communication. 18:141-62.

Squire, K., \& Barab, S. (2004). "Replaying History: Engaging Urban Underserved Students in Learning World History through Computer Simulation Games." Proceedings of the Sixth International Society of the Learning Sciences, Santa Monica, CA

Stern, Eliahu, Ori Gudes and Tal Svoray. (2009). "Web-based and traditional public participation in comprehensive planning: a comparative study." Environment and Planning B. 36, 1067-85.

Swedish Centre for Architecture and Design. (2013). "Blockholm: The Fantastic City." Retrieved at: blockholm.com

Townsend, Leanne, Arjuna Sathiaseelan, Gorry Fairhurst, Claire Wallace, (2013). "Enhanced broadband access as a solution to the social and economic problems of the rural digital divide." Local Economy. 26(6), p. 580-595.

Twitchen, Christopher and David Adams. (2011) "Increasing levels of public participation in planning using web 2.0 technology." Centre for Environment and Society Research Working Paper series no. 5. Birmingham City University.

Van Herzele, A. (2004) "Local Knowledge in Action: Valuing Nonprofessional Reasoning in the Planning Process." Journal of Planning Education and Research. 24(2): 197-212.

Weber, L. M., Loumakis, A. \& Berman, J. (2003). "Who participates and why? An analysis of citizens on the Internet and the mass public." Social Science Computer Review. 21(1), p. 26-42.

Williamson, Wayne \& Bruno Parolin. (2013). "Web 2.0 and Social Media Growth in Planning Practice: A Longitudinal Study." Planning, Practice \& Research. 28(5), 544-62.

Wilson, Michael and Roger Sapsford. (2006). “Asking Questions." Data Collection and Analysis. Ed by Roger Sapsford and Victor Jupp. 2nd ed.

Yang, Kaifeng and Sanjay K. Pandey. (2011). "Further Dissecting the Black Box of Citizen Participation: When Does Citizen Involvement Lead to Good Outcomes?" Public Administration Review. NovemberDecember, p. 880-892. 
Zhong, Zhi-Jin. (2011). "The effects of collective MMORPG (Massively Multiplayer Online Role-Playing Games) play on gamers' online and offline social capital." Computers in Human Behavior. 27, 2352-63. 